\title{
Local DNA methylation helps to regulate muscle sirtuin 1 gene expression across seasons and advancing age in gilthead sea bream (Sparus aurata)
}

Paula Simó-Mirabet, Erick Perera, Josep Alvar Calduch-Giner and Jaume Pérez-Sánchez ${ }^{*}$ (D)

\begin{abstract}
Background: Sirtuins (SIRTs) are master regulators of metabolism, and their expression patterns in gilthead sea bream (GSB) reveal different tissue metabolic capabilities and changes in energy status. Since little is known about their transcriptional regulation, the aim of this work was to study for the first time in fish the effect of age and season on sirt gene expression, correlating expression patterns with local changes in DNA methylation in liver and white skeletal muscle (WSM).
\end{abstract}

Methods: Gene organization of the seven sirts was analyzed by BLAT searches in the IATS-CSIC genomic database (www.nutrigroup-iats.org/seabreamdb/). The presence of CpG islands (CGIs) was mapped by means of MethPrimer software. DNA methylation analyses were performed by bisulfite pyrosequencing. A PCR array was designed for the simultaneous gene expression profiling of sirts and related markers (cs, cpt1a, pgcla, ucp 1, and ucp3) in the liver and WSM of one- and three-year-old fish during winter and summer.

Results: The occurrence of CGIs was evidenced in the sirt1 and sirt3 promoters. This latter CGI remained hypomethylated regardless of tissue, age and season. Conversely, DNA methylation of sirt1 at certain CpG positions within the promoter varied with age and season in the WSM. Among them, changes at several SP1 binding sites were negatively correlated with the decrease in sirt1 expression in summer and in younger fish. Changes in sirt1 regulation match well with variations in feed intake and energy metabolism, as judged by the concurrent changes in the analyzed markers. This was supported by discriminant analyses, which identified sirt 1 as a highly responsive element to age- and season-mediated changes in energy metabolism in WSM.

Conclusions: The gene organization of SIRTs is highly conserved in vertebrates. GSB sirt family members have CGIand non-CGI promoters, and the presence of CGls at the sirt1 promoter agrees with its ubiquitous expression. Gene expression analyses support that sirts, especially sirt1, are reliable markers of age- and season-dependent changes in energy metabolism. Correlation analyses suggest the involvement of DNA methylation in the regulation of sirt1 expression, but the low methylation levels suggest the contribution of other putative mechanisms in the transcriptional regulation of sirt1.

Keywords: Fish, Sirtuins, DNA methylation, Epigenetic marks, Skeletal muscle, Age, Season

\footnotetext{
* Correspondence: jaime.perez.sanchez@csic.es

Nutrigenomics and Fish Growth Endocrinology Group, Institute of Aquaculture Torre de la Sal, IATS-CSIC, 12595 Ribera de Cabanes s/n, Castellón, Spain
}

C C The Author(s). 2020 Open Access This article is licensed under a Creative Commons Attribution 4.0 International License, which permits use, sharing, adaptation, distribution and reproduction in any medium or format, as long as you give appropriate credit to the original author(s) and the source, provide a link to the Creative Commons licence, and indicate if changes were made. The images or other third party material in this article are included in the article's Creative Commons licence, unless indicated otherwise in a credit line to the material. If material is not included in the article's Creative Commons licence and your intended use is not permitted by statutory regulation or exceeds the permitted use, you will need to obtain permission directly from the copyright holder. To view a copy of this licence, visit http://creativecommons.org/licenses/by/4.0/ The Creative Commons Public Domain Dedication waiver (http://creativecommons.org/publicdomain/zero/1.0/) applies to the data made available in this article, unless otherwise stated in a credit line to the data. 


\section{Background}

Aquaculture is a fast-growing food production sector [1], but the maintenance of the current growing trend will rely on a deeper understanding of the genetic and downstream physiological mechanisms affecting productive traits. Biomarkers that identify and follow up desired traits are especially appropriate for the selection of environmental conditions and genotypes that promote or exhibit better physiological performances [2-4]. This is of particular relevance for productive traits related to intermediary metabolism that are not easy to measure (e.g., feed efficiency, energy status, redox homeostasis). Gene expression patterns of growth-promoting factors and antioxidant markers or lipid- and energymetabolism-related markers have become highly informative for disclosing different metabolic features in challenged fish and higher vertebrates [5-7]. In this sense, sirtuins (SIRTs) are a conserved family of enzymes that couple protein deacylation with the energy status of the cell via the cellular $\mathrm{NAD}^{+} / \mathrm{NADH}$ ratio, linking nutrition and energy status with epigenetic regulation [8-10]. Particularly in gilthead sea bream (Sparus aurata) (GSB), the patterns of sirt gene expression are powerful biomarkers at the tissue-specific level, as they disclose different energy statuses resulting from nutrient availability or growth potentiality $[4,11,12]$.

On the other hand, there is a growing interest in epigenetic markers because they are relatively stable and provide information about gene function and environmental interactions [13, 14]. Epigenetic mechanisms include changes in DNA methylation, histone modifications and noncoding RNA regulation that collectively affect chromatin architecture and the accessibility of the transcriptional machinery to genetic loci $[15,16]$. Concretely, DNA methylation at promoter regions reduces gene expression by impairing the binding of transcriptional activators, whereas histone acetylation generally provides a permissive environment for transcription [17, 18], also as part of the DNA demethylation machinery [19]. Differentiated cells develop a relatively stable and unique DNA methylation pattern that regulates tissuespecific gene transcription and the precise tuning of different biological processes, particularly under conditions where the environment is manipulated or natural variation exists through life cycle or livestock production [20]. In fish, good examples of this are sex determination in European sea bass [21] and tongue sole [22], early maturation [23] and muscle development in Atlantic salmon [24], larval metamorphosis in the sea lamprey [25], growth traits and osmotic regulation in the tongue sole $[26,27]$, migration propensity in rainbow trout [28], and adaptive plasticity to freshwater and marine conditions in stickleback [29]. In GSB, there is abundant literature showing the effects of temperature on different aspects of intermediary metabolism, including changes in the expression of TFs, membrane translocases, molecular chaperones, and rate-limiting enzymes of fatty acid $\beta$ oxidation and the tricarboxylic acid cycle [30, 31]. However, how temperature and other biotic and abiotic factors affect the local DNA methylation of sirts or other key regulatory genes of energy metabolism remain poorly studied in fish. In contrast, there is abundant literature on the aging-mediated effects of DNA methylation and SIRT regulation and function in humans and rodents [32].

Since methylated cytosines are found primarily at $\mathrm{CpG}$ dinucleotides and CpG-rich regions (called CG islands, CGIs) span a number of promoters of annotated genes in higher vertebrates [33], the double aim of the present study was i) to map CGIs across the gene sequences of GSB sirts and ii) to correlate changes in gene expression and CGI methylation signatures using one- and threeyear-old fish sampled in winter and summer as experimental models. Liver and white skeletal muscle (WSM) were chosen as target tissues because of their central role in fish metabolism, to provide new insights into the regulation and action of sirts in protandric hermaphroditic GSB, which is now highly cultured throughout the Mediterranean region.

\section{Methods}

Experimental fish, husbandry conditions and sampling One- $(+1)$ and three- $(+3)$ year-old GSB of Atlantic origin ('strain 1' in [4]) were reared at the indoor experimental facilities of the Institute of Aquaculture Torre de la Sal (IATS-CSIC) in 3000-L tanks under natural photoperiod and temperature conditions at the IATS-CSIC latitude $\left(40^{\circ} 5 \mathrm{~N} ; 0^{\circ} 10 \mathrm{E}\right)$. Water temperature ranged from $10{ }^{\circ} \mathrm{C}$ in winter to $27^{\circ} \mathrm{C}$ in summer. The water oxygen concentration was always higher than $75 \%$ saturation, and unionized ammonia remained below toxic levels (< $0.02 \mathrm{mg} / \mathrm{L}$ ) irrespective of season. Fish were fed a standard commercial diet (EFICO YM 568; BioMar, Dueñas, Spain) once a day until visual satiety (3,5 or 6 times per week depending on season and fish size). At the winter and summer sampling points, 10 fish per age class (class $+1,50-115$ g body weight; class $+3,1 \mathrm{~kg}$ body weight) were anesthetized with 3-aminobenzoic acid ethyl ester (MS-222, $100 \mu \mathrm{g} / \mathrm{mL}$ ), and the liver and WSM were rapidly excised, frozen in liquid nitrogen and stored at $80^{\circ} \mathrm{C}$ until RNA and DNA extraction.

\section{In silico analyses}

Gene organization of GSB sirts was analyzed by BLAT searches in the IATS-CSIC genomic database of GSB (http://nutrigroup-iats.org/seabreamdb/). The retrieved sequences were manually curated by aligning genome sequences (Clustal X) with GSB sirts transcripts [11], 
using the online tool FGENESH from softberry for predicting gene structure [34]. For comparative purposes, the seven human and zebrafish SIRT counterparts were obtained from the ENSEMBL database (www.ensembl. org). Graphical representations were carried out with the online tool Exon-Intron Graphic Maker (http://wormweb.org/exonintron). Polyadenylation sites were identified by means of the Softberry POLYAH (www.softberry. com). Predictions of putative transcription start sites (TSSs) were performed by means of Promoter 2.0 (www. cbs.dtu.dk/services/Promoter/) [35]. Core promoter regions were predicted by using two complementary approaches: the Easy Promoter Prediction Program (EP3), which uses the GC content and structural features of DNA to identify promoter regions [36], and MatInspector (www.genomatrix.de), which searches transcription factor binding sites (TFBSs) and TFBS-containingpromoter modules. In addition to TFBSs retrieved from MatInspector, searches in an $\sim 1-\mathrm{kb}$ region upstream of the TSS and in the first exon for TFBSs known to be present in SIRT promoters of higher vertebrates were performed by ConTra v3 (http://bioit2.irc.ugent.be/contra/v3/\#/step/1) [37] using the TRANSFAC database, with sensitivity and accuracy set at core match $=0.95$ and matrix match $=0.85$. Predictions of CGIs through the entire gene, including a 2-kb region upstream of the TSS, were performed by means of MethPrimer software (www.urogene.org/methprimer/). The search parameters used were length $\geq 200, C+G$ content $\geq 50 \%$, ratio of observed $/$ expected $\mathrm{CpGs} \geq 0.60$ and window size $=100$.

\section{DNA isolation and bisulfite conversion}

Tissue DNA was extracted using the Quick-DNA ${ }^{\text {tu }}$ Miniprep Plus Kit (Zymo Research, Irvine, CA, USA) following the manufacturer's instructions. The quantity and quality of DNA were assessed by a NanoDrop 2000c Spectrophotometer (Thermo Fisher Scientific, Waltham, MA, USA), and DNA integrity was analyzed in a $1 \%$ agarose gel. Extracted DNA was bisulfite converted using the EZ DNA Methylation Gold bisulfite conversion kit (Zymo Research, Irvine, CA, USA) following the manufacturer's instructions.

\section{PCR of bisulfite-converted DNA}

Primers were designed using PyroMark Assay Design 2.0.01.15 (Qiagen, Hilden, Germany) to hybridize CpGfree sites at the highest melting temperature (Additional file 1: Table S1). Reverse primers were labeled with biotin at the $5^{\prime}$-end, and bisulfite-converted DNA was amplified by PCR using Invitrogen ${ }^{\mathrm{Tm}}$ Platinum $^{\mathrm{Tm}}$ Taq Hot-Start DNA Polymerase (Thermo Fisher Scientific, Waltham, MA, USA) with forward- and reverse-specific primers at $1 \mu \mathrm{M}$ each in a total volume of $25 \mu \mathrm{L}$. The reaction was performed in a Touchgene Gradient Thermal
Cycler (Techne, Cambridge, UK) as follows: $95^{\circ} \mathrm{C}$ for 5 min; followed by 35 cycles of $95^{\circ} \mathrm{C}$ for $45 \mathrm{~s}, 60^{\circ} \mathrm{C}$ for 45 $\mathrm{s}$, and $72{ }^{\circ} \mathrm{C}$ for $1.5 \mathrm{~min}$; with a final extension at $72{ }^{\circ} \mathrm{C}$ for $5 \mathrm{~min}$. PCR products were checked by $1 \%$ agarose gels to ensure specificity before pyrosequencing.

\section{Pyrosequencing and DNA methylation analyses}

Pyrosequencing analysis was performed as described previously [38]. Briefly, primers for pyrosequencing (Additional file 1: Table S1) were designed using PyroMark assay design 2.0.01.15. The Vacuum Prep Tool (Biotage, Uppsala, Sweden) was used to prepare singlestranded PCR products according to the manufacturer's instructions. Pyrosequencing reactions were performed in a PyroMark Q24 System version 2.0.6 (Qiagen, Hilden, Germany). Data were analyzed using PyroMark Q24 software, and the quantification of methylation was attained from the average of individual CpGs included in the analyzed sequence.

\section{Gene expression analyses}

RNA was extracted using the MagMAX-96 total RNA isolation kit (Life Technologies, Carlsbad, CA, USA). The RNA yield was 50-100 $\mu$ g, with absorbance ratios (A260/A280) of 1.9-2.1. RNA integrity number (RIN) values of 8-10 (Agilent 2100 Bioanalyzer; Agilent, Santa Clara, CA, USA) were indicative of clean and intact RNA. Reverse transcription of 500 ng of total RNA was performed with random decamers using a High-Capacity cDNA Archive Kit (Applied Biosystems, Foster City, CA, USA). Negative control reactions were run without reverse transcriptase. A 96-well PCR array of 11 markers of metabolic condition was designed for simultaneous gene expression profiling of liver and WSM. Two housekeeping genes ( $\beta$-actin and 18S rRNA) and controls for PCR performance were included in each array. Briefly, $660 \mathrm{pg}$ of total cDNA was used in $25 \mu \mathrm{L}$ PCR reactions. PCR wells contained 2x SYBR Green Master Mix (BioRad, Hercules, CA, USA) and specific primers at a final concentration of $0.9 \mu \mathrm{M}$ (Additional file 2: Table S2). All pipetting operations for the PCR arrays were performed by an EpMotion 5070 Liquid Handling Robot (Eppendorf, Hamburg, Germany) to improve data reproducibility. Real-time quantitative PCR was carried out in an Eppendorf Mastercycler Ep Realplex (Eppendorf, Hamburg, Germany). The PCR amplification program consisted of an initial denaturation step at $95^{\circ} \mathrm{C}$ for $3 \mathrm{~min}$, followed by 40 cycles of denaturation for $15 \mathrm{~s}$ at $95^{\circ} \mathrm{C}$ and annealing/extension for $60 \mathrm{~s}$ at $60^{\circ} \mathrm{C}$. The efficiency of the PCR reactions was consistently higher than $90 \%$ and similar among all the genes. The specificity of the reactions was verified by melting curve analysis (ramping rates of $0.5^{\circ} \mathrm{C} / 10 \mathrm{~s}$ over a temperature range of 55$95^{\circ} \mathrm{C}$ ). Negative controls without a template were 
performed for each primer set. Gene expression was calculated using the delta-delta Ct method [39]. For multigene analysis, all values for a given tissue were referenced to the summer expression level of sirt1 in +3 fish, for which a value of 1 was arbitrarily assigned. Foldchanges in gene expression were calculated as the expression ratio between $+3 /+1$ fish. A value $>1$ indicates higher expression levels in +3 fish, and values $<1$ indicate lower expression levels in +3 fish.

This manuscript follows the ZFIN Zebrafish Nomenclature Guidelines for gene and protein names and symbols (https://wiki.zfin.org/display/general/ZFIN+Zebrafish+Nomenclature+Conventions).

\section{Statistical analysis}

Normality and equal variance of data were tested by the Shapiro-Wilk and Levene tests, respectively. Changes in DNA methylation at individual CpG sites were analyzed by Student's t-test. The effect of age and season on the gene expression of sirts and related markers in the liver and WSM was analyzed by Student's t-test and two-way analysis of variance. The relationship between sitespecific DNA methylation and gene expression was assessed by Pearson correlation analysis. The significance level was set to $P<0.05$ for all tests performed. These analyses were performed using SigmaPlot version 13.0 (Systat Software, San Jose, CA, USA). Supervised multivariate analysis partial least-squares discriminant analysis (PLS-DA) was applied using EZ-INFO ${ }^{\circ}$ v3.0 (Umetrics, Umeå, Sweden) to depict the contribution of analyzed genes to group discrimination. The quality of the PLS-DA model was evaluated by the parameters R2Y (cum) and Q2 (cum), which indicate the fit and prediction ability, respectively. To discard the possibility of overfitting of the supervised model, a validation test consisting of 500 random permutations was performed using SIMCA-P+ v11.0 (Umetrics, Umeå, Sweden). The relative relevance of genes in the discriminant functions was assessed by the variable importance in projection (VIP) values. A VIP score $>1$ was considered to be an adequate threshold to determine discriminant variables in the PLS-DA model [40-42].

\section{Results}

\section{Sirtuin gene structure and regulatory elements}

The seven sirt gene sequences of GSB were uploaded to GenBank with accession numbers MN123792-MN123 798. These genes have a variable number of exons that range from 3 in sirt4 to 16 in sirt2 (Fig. 1a). When comparisons were made within and among the seven SIRT orthologous genes of human, zebrafish and GSB, the entire gene length varied from $1.4 \mathrm{~kb}$ to $48.3 \mathrm{~kb}$, with the exception of sirt6 of zebrafish, which contains several long introns that increase the gene length from the start to the stop codon up to $136.5 \mathrm{~kb}$. Despite this, the number and size of exons seems to be highly conserved for each SIRT gene through vertebrate evolution (Fig. 1b).

The occurrence of CGIs close to TSSs of GSB sirts was evidenced in the case of sirt1 and sirt3. The CGI of GSB sirt1 is 473 base pairs (bp) in length, comprising $100 \mathrm{bp}$ of the $5^{\prime}$ untranslated region (5'UTR), $349 \mathrm{bp}$ downstream of the ATG start codon and $24 \mathrm{bp}$ from the first intron (Fig. 2a). GSB sirt3 has a shorter CGI (229 bp), which comprises 118 bp from the $5^{\prime}$ flanking region and $111 \mathrm{bp}$ downstream of the TSS, corresponding to the first noncoding exon (Fig. 3a). Further analysis highlighted a sirt1 gene structure with an open reading frame (ORF) of $2093 \mathrm{bp}$ and a 3'UTR of $1583 \mathrm{bp}$ until the predicted canonical polyadenylation signal. Likewise, sirt 3 contains an ORF of $1355 \mathrm{bp}$ and a 3'UTR of $411 \mathrm{bp}$ until the predicted canonical polyadenylation signal. Searches for regulatory elements in the promoter region of sirt1 ( 1 kb upstream of TSS) and in the first exon predict a wide range of multiple cis-regulatory elements (i.e., HIF1, P53, C/EBP- $\alpha$, GATA2, MYOD, FOXO1, AML1, PPAR $\gamma$, GATA1, HNF1, NF-kB, ETS, SP1, OCTAMER, PIT1, XBP1, MYC and CHREBP) (Fig. 2b). Some of them were also retrieved in the promoter region of sirt3 (i.e., GATA1, GATA2, OCTAMER, HNF1, AML1, NF-kB, MYC, and SP1), while others seem to be exclusive to sirt3 (i.e., TBP, AP1, PBX1, CREB, NRF2, HTF, CHREBP, ZF5, SOX6, ERR- $\alpha$, and MYF) (Fig. 3b).

\section{Sirtuin 1 and 3 promoter methylation}

Up to 4 CpG sites at the CGI of the sirt3 promoter were chosen for methylation analyses of liver and WSM in fish of two age classes at two critical windows along the production cycle (winter and summer). These CpGs remained generally hypomethylated regardless of age, tissue and season (Fig. 4). However, analyzing individual positions, the CpG2 site consistently showed the highest methylation level, although it did not match with key TFBSs (Fig. 3b). The CGI of the sirt1 promoter was also hypomethylated without a clear pattern of methylation among the 22 analyzed CpG sites in the liver (Fig. 5) and WSM (Fig. 6). Moreover, this CGI remained hypomethylated when comparisons were made at the hepatic level between the two age groups in both winter and summer (Fig. 5a, b). The same was found in the WSM for fish sampled in winter (Fig. 6a). However, in summer, 15 out of 22 CpG sites (69\%) shared a higher methylation in young fish (Fig. 6b). This observation was more evident for the first three CpG sites, with the CpG2 and CpG3 sites reaching the highest level of methylation $(\sim 4 \%)$. The methylation levels of the CpG19 and CpG20 sites were also high in young fish. Of note, SP1 binding sites are close or within all these responsive positions. The involvement of this TFBS in 


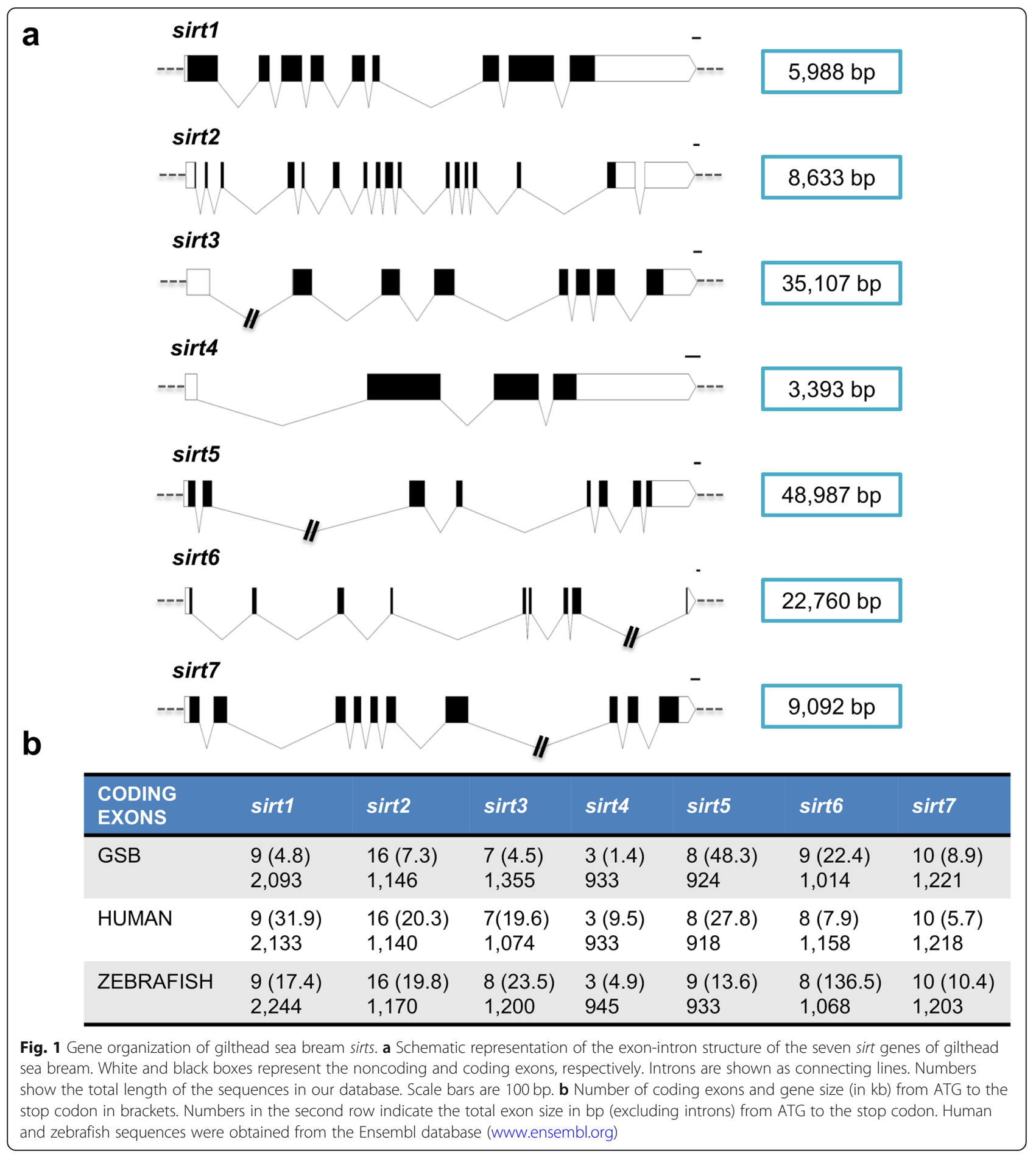

sirt1 regulation was reinforced by regression and Pearson correlation analyses, which showed across individuals a statistically significant negative correlation between WSM sirt1 gene expression and the methylation level of the sirt1 CGI promoter at the CpG3 $(R=-0.66 ; P=0.01)$ (Fig. 6c) and CpG19 $(R=-0.74 ; P=0.004)$ sites despite lower methylation levels in the latter.
When comparisons were made on a seasonal basis, the DNA methylation was increased in summer (Fig. 7a). This was especially evident in the +1 class, and a negative correlation was found between sirt1 gene expression and the averaged methylation level of the CpG2 and CpG3 sites $(R=-0.658 ; P=0.008)$ (Fig. $7 \mathrm{~b})$. The same trend was reported for the CpG12-14 
a

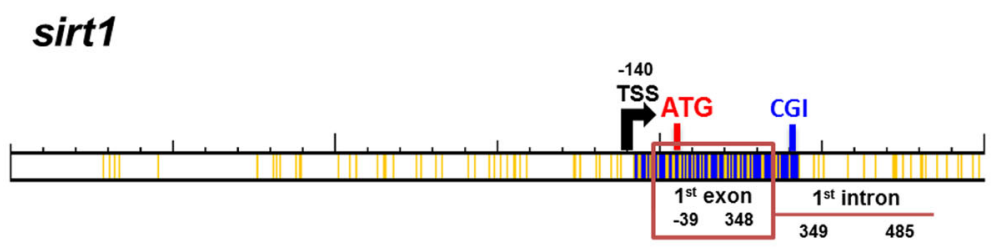

CGI length: 473

CGI location: -101 to 371

Analyzed CpGs: 22

b

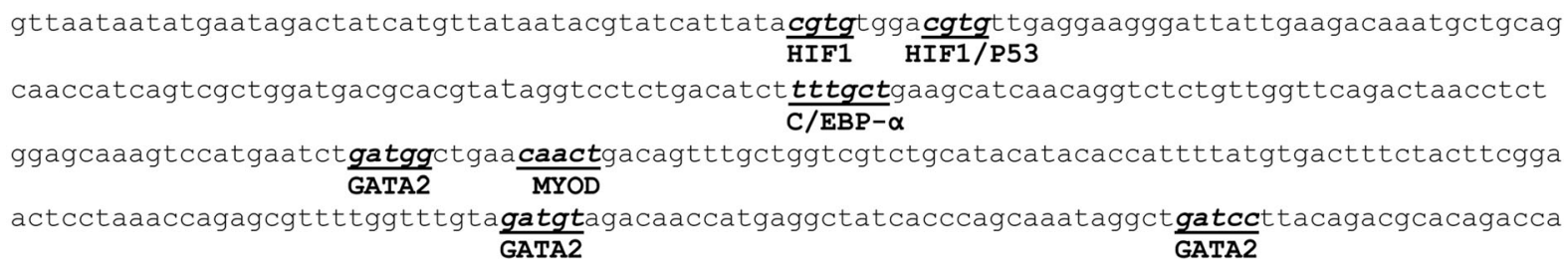
Caacttaccgacgacagttcatcacatcctaatagaccgtagtaatcctccaagtcctctggtttgcagttcaaaacagcatccatgaaatc FOXO1

tgatttgtgtgtaacgttagtttctggttgcggagcagcttctgctatcctggatcacagctgtggttcaagagtcgctgatggggtccac GATA2 C/EBP- $\alpha$ GATA2 MYOD AML1 GATA2

ctcgctgctgctgctgctgtgggtcactcactcactatatcctcaaagctgaactttttttaaatgatttggtcagctagctttgcgtcaa PPARY GATA2 PPARY C/EBP- $\alpha$

taattgattaactgcgaactggttaaagtaatcaagggagatctctcctgactgactcgtggggaaaagtcagcgctccctttcactgtatg GATA1 NNF1 NFB GATA2

acgcatgctgcattcaagtgccgaactaaaactcacactcggctcgaaatttccagcattcacggggtaccaggcaaaggcggaggt [tatt ETS

qgaacacatgatacattagtctgacataaaaaaatgatgtctttgatgacaaggttgtgtggcatatgtggctaaattaatgtaatacat $\overline{\text { GATA1} / 2}$

GATA2

ttgcaagaggcatgcaattaaggctttcattaaattgcaacgtcttcgtgtattttaaacgttataaaagggatgtattcacaaagctca C/EBP- $\alpha$ Octamer/P53 $\overline{\text { C/EBP }-\alpha}$ GATA2

catgctgttatcaaaaagtt ttccgtgtgcgtttgatgcataattgtttgcagttattcatgagcgctcacctttgccaaaattaatccgac ETS GATA2 FOXO1 $\overline{\text { PIT1 }}$ C/EBP- $\alpha$

agcgtttgaaggcagcaatattttgttatggttttatgtgatagacgttagaagggggcgttctcgtcctgactactggtggagaacgagtc TSS GATA1/2 SP1 CpG3

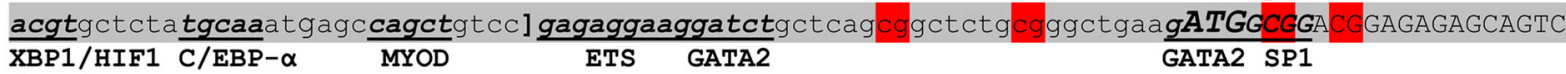
/MYC/CHREBP

TCGGAACGGCCTTCTCAGGCGCCTCCGAAATGGAAGAACCAGCCGCAAAAAGGTCGAAAATCAGTCCGTTGACTAACTACGGATTCAAAGTC GCCAAAGCGGACCAGTTATCAGGCCTCCCGGGGGCCACTGAGAGCTGGGAGGCGGCGGTGGATTGTGCGCAGCCAGCGGAGAAGGAAGCGAA GCCGGTGATGGCGGTAGAGCAGGCCCCAGCGGCAGCGCTAGGCGGAGACAACAATGGACTGGGAATGCTGGTCTCCGAGTCGCACAAACCAG PPARY GATA2 SP1 CPG19 SP1 SP1

TAGTGAAACTAGACGACGGCGCTGTGCTCGGGACAACCGAGGAGGGTGCTG (intron 1, 484 bp) ATTTTCTTGGACATGACGATCTC

Fig. 2 CpG islands and regulatory elements in sirt1 of gilthead sea bream. a Schematic representation of the CpG islands (CGIs) in sirt1 of gilthead sea bream (in blue). Yellow lines represent CpG sites. Numbers indicate the position of the putative transcription start site (TSS, black arrow) and the starting and ending point of the first exon (red box) and intron (red line) with respect to the start codon (ATG, red). b Regulatory elements in sirt 1 of gilthead sea bream. The first intron sequence was replaced by an indication of their length. Lower case letters indicate a 2-kb sequence upstream of the translational start site ATG and include the $5^{\prime}$ UTR and the $5^{\prime}$ flanking region. The predicted core promoter region is flanked by brackets. The putative TSS is shaded in black. Predicted regulatory elements are indicated in bold, underlined, and lower case italics. CGI is shaded in gray. The analyzed CpG positions are shaded in red. This CGl spans the first exon and expands into the first intron (not shown)

and CpG16 sites $(R=-0.679 ; P=0.002)$, with these positions close or within SP1 binding sites. However, changes observed in cytosine methylation at the remaining positions did not correlate with gene expression.

\section{Gene expression profiling}

Gene expression profiling of all members of the sirt gene family in combination with related markers of energy metabolism is summarized in Table 1. A statistically significant effect of season (two-way ANOVA) was found 


\section{a sirt3

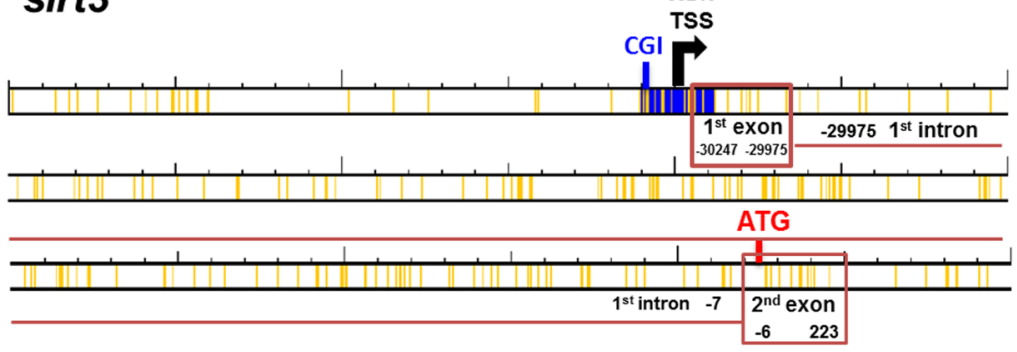 \\ CGI length: 229 \\ CGI location: -30364 to -30136 \\ Analyzed CpGs: 4 \\ b \\ gctttccatgttttttgttttgttttgttttaaatgcattattcagaataatgttcacacaattggtcgcaccagttcaatgtttaaagaac aaacaaaagataaagtaacaacaggccatggcagaataagagaatacaaaataaaatgaatacatatatattagtgacagactctcttca GATA1/2 TBP AP1 \\ ggcaaataattcaaagtaaatattaattgctgaaatgcattccttgttggtgaccagtttaacagactcaaagaaacaatcaactaggcttt OCTAMER AP1 $\overline{\mathrm{PBX} 1}$ \\ tcacaataaaggtacagaagcttgaatgattgtgtagcagaacacaggtgtatgaaaccttctgtatgtaatataataatcaagtttacat PBX1 \\ gcaatcaaattcttaaagtcgctgtattcgacta [ttaattaattcagttattcattttgagtgtagtcacacagttgtatctgtatatgc HNF1 \\ actgttgggtagtttatttttatttaaagaaaaaaacaacaaatacatttcacaagcttttctttgttttgcatgcaaccaaaaaaatgtg TBP \\ taaagttgcctaacaagccaccacagctgtctgatatctcagatatttccctctgagaaaaatgtctcgcagcagaagtagaaagaagtcaa GATA1 GATA1 \\ gtgaagtacaaatacctcacatttgtatacaagtgcagtacttgtagtagatgtactgacgtgatgggacgctggggtcgggaagcggaaat acacacccacgtgactgcagctctgtttcccgcccgtatgttaatgagttattgaggacccggaacag] cagcagagtgacagctctgtc MYC/HTF AP1 $\frac{\text { TSS }}{\text { AP1 }}$ ERR- $\alpha$ /CHREBP $\underline{\boldsymbol{c}}$ tctaaagctctcggctccaggccgctgcgtgcagacaaghttcgtgtttttcaggagaaggagacgcttttactgctgctggagctcatgt ZF5 SOX6 \\ tagagctgcggggtgatacactcacagcttaaaggttcaagaagctcccgagttcccccctctttttttgttttttggatgtggagcatccc GATA1 \\ gagtggctgaacgaagtcaccgccgtctgctcagcattcaaaaggtcogccaactggagagccaggt (intron 1, 29968 bp)gttgg ERR- $\alpha$ MYF \\ aATAACAGGTCCAGGTCCAGCTGCGATAAAAAAGCCGCCCAGCCTCCAGTCACCAGGTTAACTCGCAGCTCCAGCAGCACCCAGAGCAG \\ Fig. $3 \mathrm{CpG}$ islands and regulatory elements in sirt3 of gilthead sea bream. a Schematic representation of the CpG island (CGI) in sirt3 of gilthead sea bream (in blue). Yellow lines represent CpG sites. Numbers indicate the position of the putative transcription start site (TSS, black arrow) and the starting and ending point of the first exon (red box) and intron (red line) with respect to the start codon (ATG, red). b Regulatory elements in sirt3 of gilthead sea bream. The first intron sequence was replaced by an indication of their length. Lower case letters indicate a 2.37-kb sequence upstream of the translational start site ATG and include the first exon and the first intron, as well as the $5^{\prime}$ UTR and the $5^{\prime}$ flanking region. The putative TSS is shaded in black. Predicted regulatory elements are indicated in bold, underlined, lower case italics. CGl is shaded in gray. The analyzed $\mathrm{CpG}$ positions are shaded in red}

in both liver and WSM for almost all the analyzed genes, with the exception of sirt7 and $p g c 1 \alpha$ in liver and sirt2 in WSM. However, the age effects became more evident for sirt genes in WSM than in liver. Conversely, markers of fatty acid $\beta$-oxidation (cpt1a) and mitochondrial uncoupling respiration (ucp1) were more responsive to age-mediated changes in the liver than in WSM. Additionally, as a general feature, most genes included in the array were downregulated by age at the hepatic level (Fig. 8a, b). This was especially evident for sirt1, sirt2, sirt5, cpt1a and ucp1, which were consistently downregulated in the +3 class in both winter and summer. In contrast, in WSM, most of the genes included in the array were upregulated by age in winter (Fig. 8c). This also applied in summer to sirt1, sirt2, sirt5, sirt6 and sirt7, but the opposite was found for cpt1a and ucp3 (Fig. 8d). Of note, most of these age-mediated changes in gene expression were accentuated in winter, as indicated by the statistically significant interaction of age and season in the two-way ANOVA (Table 1).

This temporal and tissue-specific regulation of gene expression is reinforced by multivariate analysis. In liver tissue, ucp 1, cpt1a and cs loadings predicted most of the observed variance, with a poor contribution of sirts, which was reduced to sirt 5 after considering five components in the PLS-DA (Fig. 9). In contrast, in WSM, the 


\section{a}

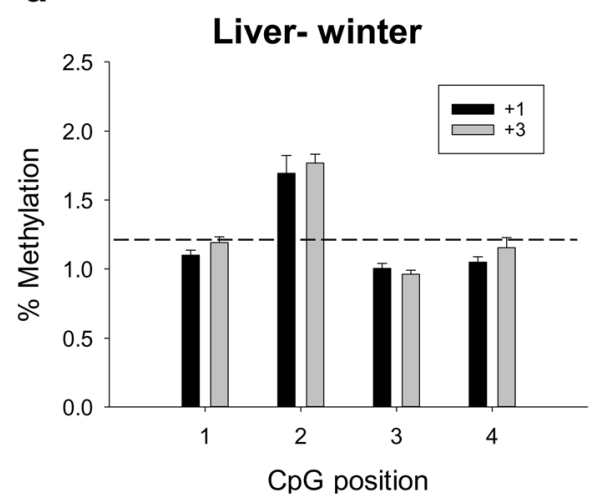

b

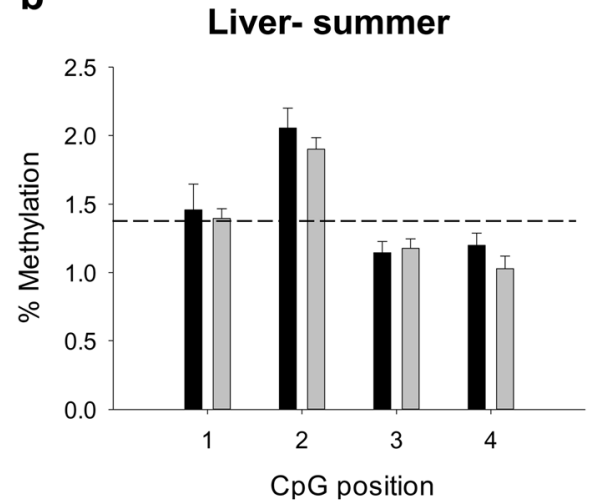

C

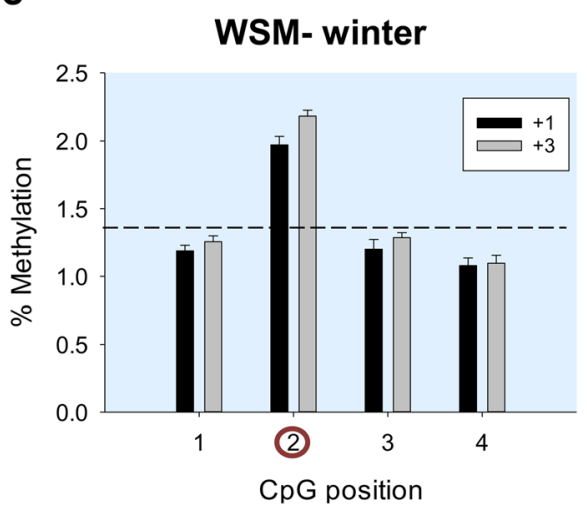

d

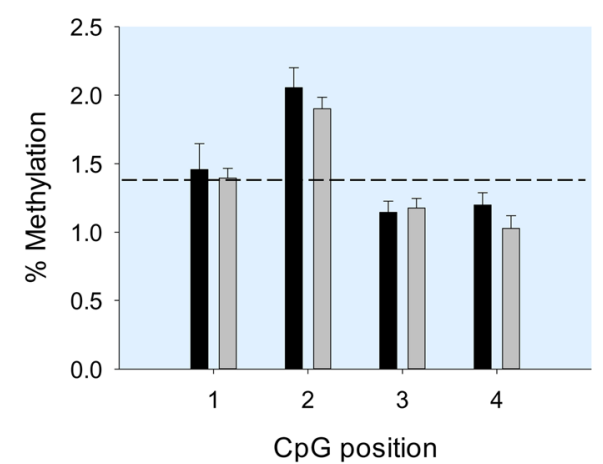

Fig. 4 Age and seasonal changes in DNA methylation of gilthead sea bream sirt3. Site-specific DNA methylation (\%) of sirt3 in liver (a, b) and white skeletal muscle (WSM) $(\mathbf{c}, \mathbf{d})$ of fish of different ages $(+3$, three-year-old; +1 , one-year-old) in winter and summer. Data are the mean \pm SEM of 8-10 fish. CpG position with a circle indicates significant differences between ages by t-test $(P<0.05)$. Dashed lines indicate the mean methylation of all individuals and positions

first three components showed cumulative values for R2Y (explained variance) and Q2 (predicted variance) of 69 and 59\%, respectively (Fig. 10a). With this dataset, the separation along the first component explained $28 \%$ of the total variance separating groups by season (winter vs summer), whereas component 2 explained $27 \%$ of the variance separating groups by age in both winter and summer (Fig. 10b). Genes with a contribution to VIP $>1$ in component 1 totaled 6, with a main contribution of sirt1, sirt5, sirt6 and sirt7. When the second component was also considered, a total of 4 genes (sirt2, sirt4, ucp3 and cpt1a) showed VIP values $>1$ (Fig. 10c).

\section{Discussion}

Gene organization of vertebrate SIRTs is highly conserved SIRTs are widely conserved among living organisms with a number that ranges from one in bacteria to seven in vertebrates [43], evidencing this gene expansion is the important role of SIRTs as key components of energy metabolism in all studied living organisms. Certainly, the seven GSB counterparts of mammalian SIRTs have a conserved Rossman fold domain, commonly found in proteins that bind $\mathrm{NAD}^{+}$or $\mathrm{NADP}^{+}$[44]. Furthermore, phylogenetic analysis of GSB Sirts rendered monophyletic clusters [11] according to the four SIRT classes described by [45]. High SIRT conservation across vertebrate evolution is also extensive to gene organization, as illustrated herein by the comparisons made among GSB, zebrafish and human SIRTs, which consist of a similar number and size of exons. However, the size of introns for members of the SIRT gene family is highly variable within and among species, probably due to the less functional constraints of noncoding DNA regions [46]. Of note, the recognized top TFBSs for human SIRT1 (C/EBP $\alpha$, MYOD and MYC) and SIRT3 (AML1, CREB, HTF, NRF2, PBX1, and TBP) [47] were also retrieved at the predicted promoter regions of GSB sirt1 and sirt3. Furthermore, in different human and rodent metabolic situations, it has been proven that SIRT1 deacetylase activity modulates the function of most transcriptional regulators (e.g., NF-кB, p53, FOXO1, PPAR $\gamma$, CHREBP, HIF1 and $\mathrm{C} / \mathrm{EBP}-\alpha$ ) forming negative feedback loops [48], which probably also occurs in fish. 

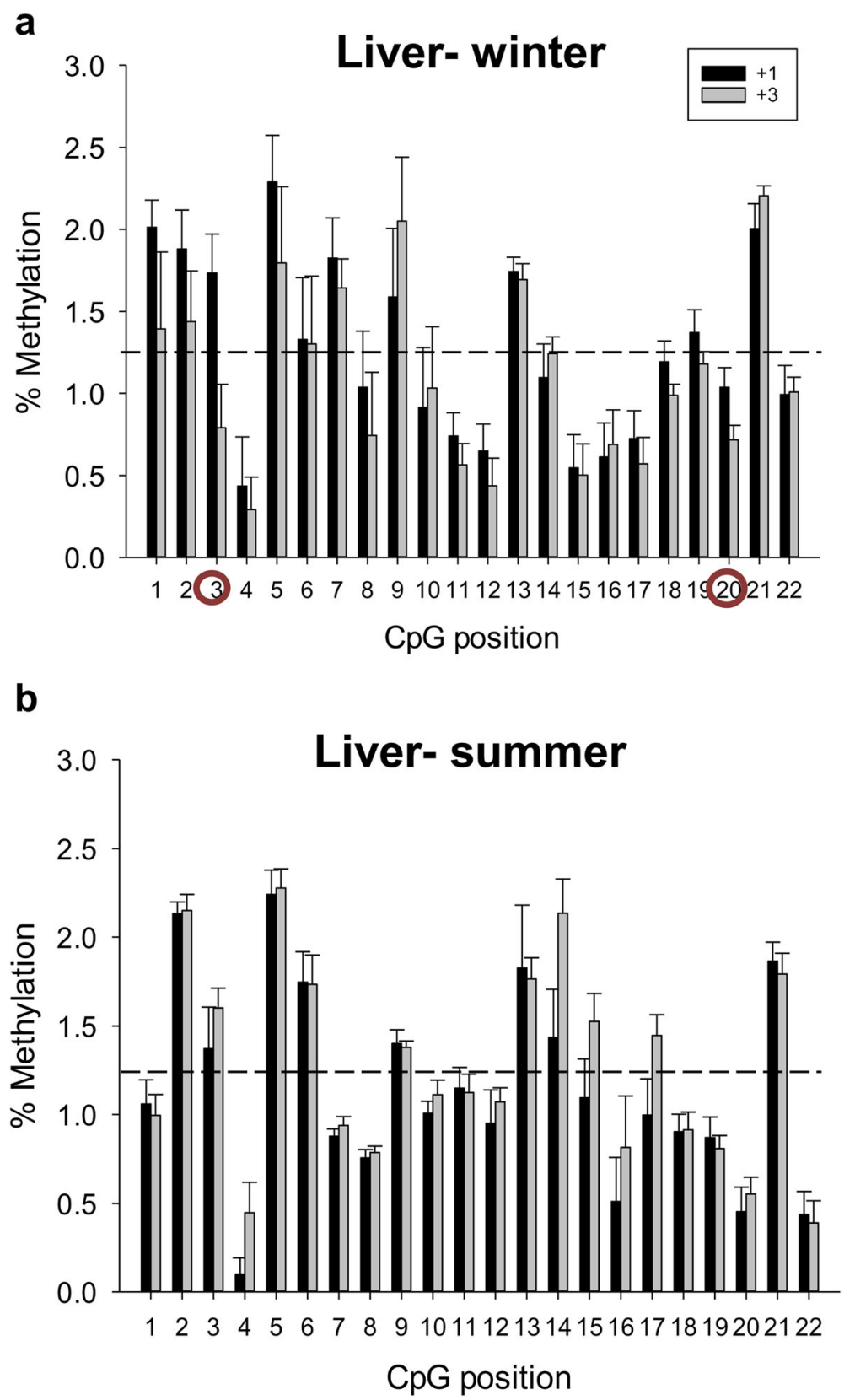

Fig. 5 Age and seasonal changes in DNA methylation of sirt1 in gilthead sea bream liver. Site-specific DNA methylation (\%) of sirt1 in the liver in winter (a) and summer $(\mathbf{b})$ of fish of different ages $(+3$, three-year-old; +1 , one-year-old). Data are the mean \pm SEM of 8-10 fish. CpG position with a circle indicates significant differences between ages by t-test $(P<0.05)$. Dashed lines indicate the mean methylation of all individuals and positions

\section{CGIs in SIRT promoters appeared early during vertebrate evolution}

The number and location of CGIs are very similar in humans and mice [49]. In contrast, the number and density of CGIs are highly variable among fish genomes $[50,51]$, although interspecies experiments in humans, mice and zebrafish demonstrate that CGIs are an evolutionarily conserved mechanism that protects DNA from methylation to shape the epigenome [52]. This notion fits well with the early appearance of CGIs during vertebrate evolution and is associated with an increased concentration of CGIs close to TSSs from cold-blooded vertebrates to warm-blooded vertebrates [53]. To the best of our knowledge, this general trend has not been assessed in SIRT genes, but interestingly, the occurrence of CGIs has been reported in SIRT promoters of humans [54-58], mice [59] and ruminants [60-62]. In contrast, in GSB, the occurrence of CGIs was only found in sirt1 


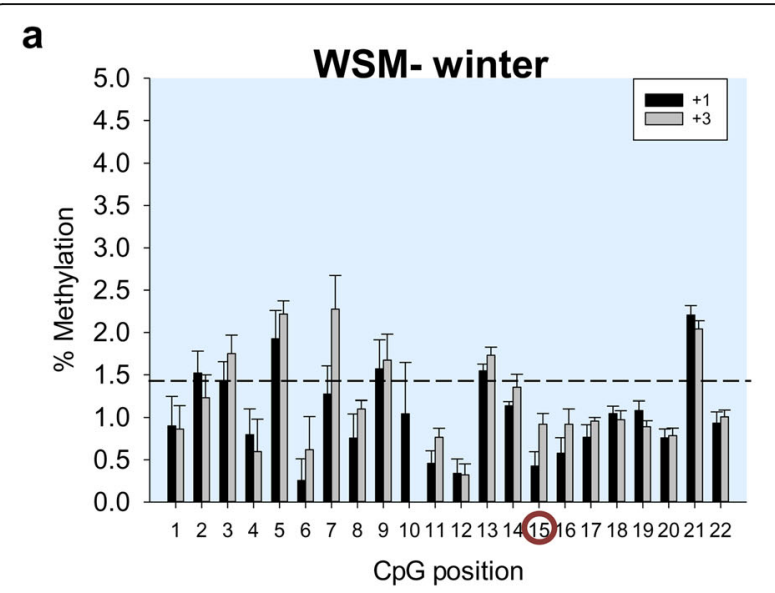

b

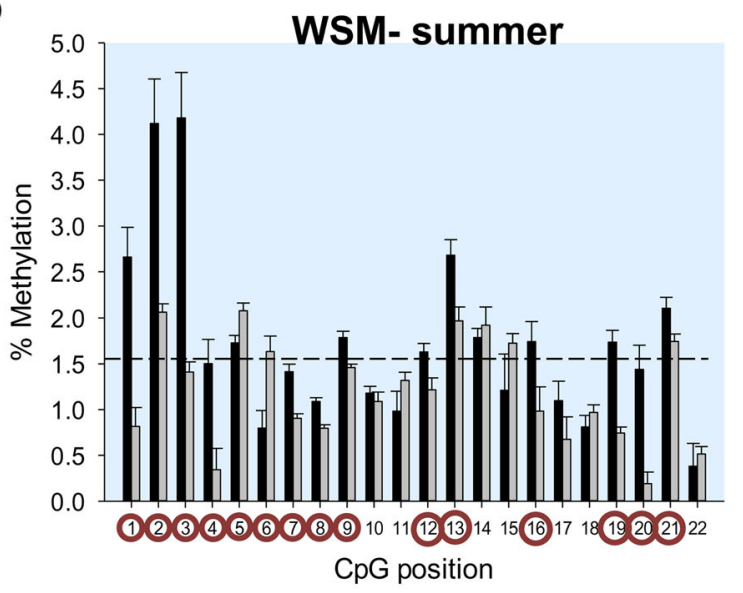

C

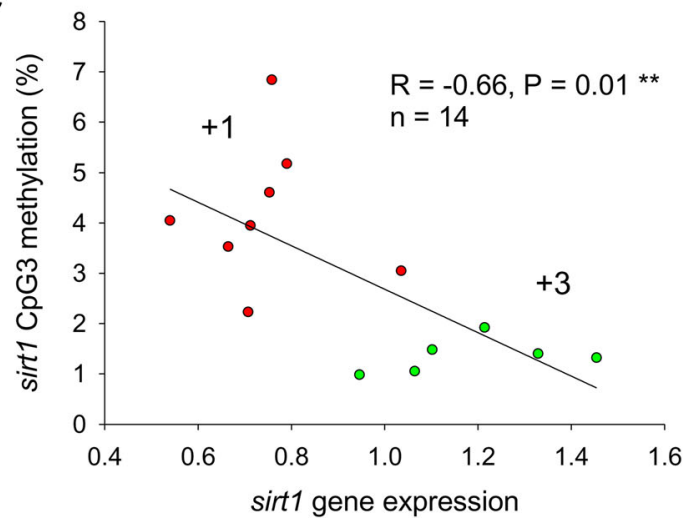

Fig. 6 Age and seasonal changes in DNA methylation and sirt1 expression in gilthead sea bream muscle. Site-specific DNA methylation (\%) of sirt 1 in white skeletal muscle in winter (a) and summer (b) of fish of different ages $(+3$, three-year-old; +1 , oneyear-old). Data are the mean \pm SEM of 8-10 fish. CpG position with a circle indicates significant differences between ages by t-test $(P<$ 0.05). Dashed lines indicate the mean methylation of all individuals and positions. (c) Correlation between DNA methylation at CpG3 in the sirt1 gene promoter region and sirt1 gene expression in white skeletal muscle (WSM) of gilthead sea bream during summer. Green and red points represent data from +3 , three-year-old and +1 , oneyear-old fish, respectively and sirt3. With the same search criteria, CGIs were also retrieved in the sirt1 promoter of fugu (Gene ID: 101061405), zebrafish (Gene ID: 797132), tilapia (Gene ID: 100700447), Atlantic salmon (Gene ID: 106576833) and Australian ghostshark (Gene ID: 103181092), which has a basal position in vertebrate evolution with respect to bony fish. However, the CGI of the GSB sirt3 promoter did not appear to be conserved in all fish species, which may suggest variations in the regulation of sirt3 through the fish lineage.

The presence of CGI- and non-CGI promoters in the GSB sirt family

CGIs allow promoter function by destabilizing nucleosomes and attracting proteins that create a transcriptionally permissive chromatin state [49]. Indeed, CGIs colocalize with a great deal of promoters in both the human and mouse genomes [49, 63, 64]. According to this, CGIs should be appropriate for modulating genes that are required to be expressed ubiquitously irrespective of cell type. In contrast, promoters without CGIs should be more suitable for responses to external/internal cues because their transcriptional on/off status could be more strictly controlled depending on the situation [53]. However, this feature is more complex within the sirt family in fish, as sirt isotypes with/without CGI promoters coexist in GSB, probably to assure ubiquitous and perhaps highly regulated activity in different tissues and metabolic conditions. Certainly, all sirts are expressed at detectable levels in 14 analyzed GSB tissues [11], and multivariate analysis highlighted a higher expression level not only of sirt 1 but also of sirt 2 and sirt5 (without a CGI promoter). However, sirt1 appeared to be one of the most ubiquitous and highly expressed isotypes when considering as a whole the entire set of analyzed tissues [11]. Conversely, sirt3, as well as sirt4, 6 and 7, was categorized as a sirt isotype with a relatively low expression level, as occurred in a previous study in metabolically active tissues (e.g., liver and WSM) [4], while this sirt isotype is able to achieve high expression in immunerelevant fish tissues (e.g., head kidney, posterior intestine) $[11,12]$. It is unknown whether CGI promoters may contribute to tissue-specific sirt3 expression patterns.

\section{Local DNA methylation might contribute to regulating sirt1 gene expression}

The connection between metabolism and epigenetics through the action of SIRTs has been widely demonstrated in higher vertebrates [9]. In fact, the deacylase activity of SIRTs over histones, TFs and epigenetic enzymes, and their requirement of $\mathrm{NAD}^{+}$as a cosubstrate, makes SIRTs transduce energy metabolic signals into the epigenetic regulation of gene expression, chromatin 


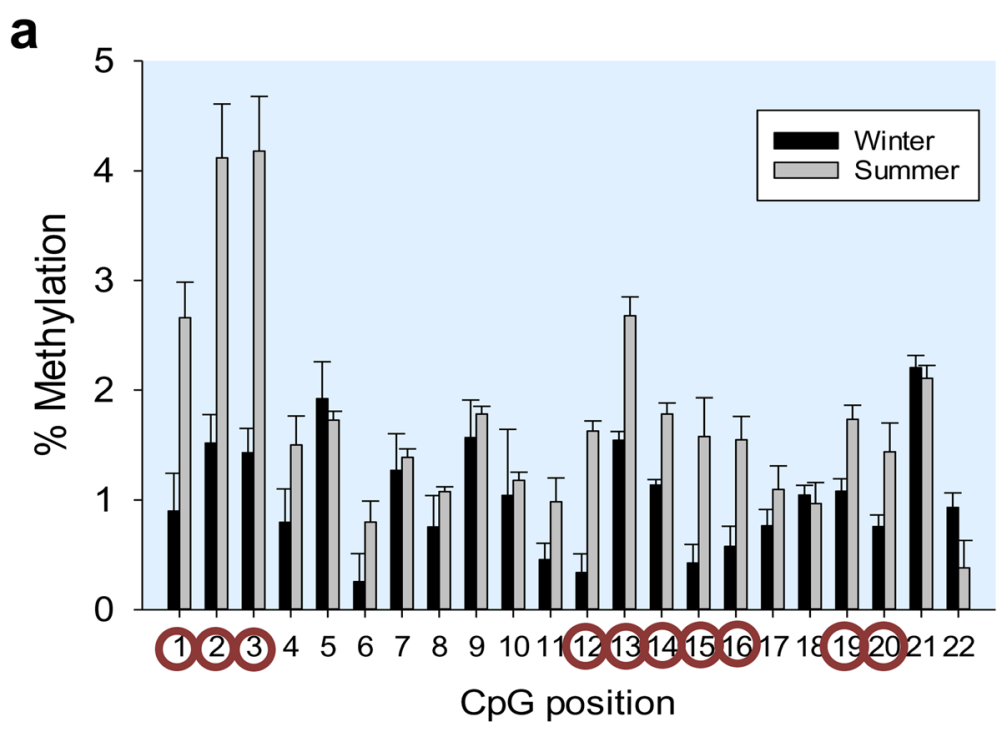

b

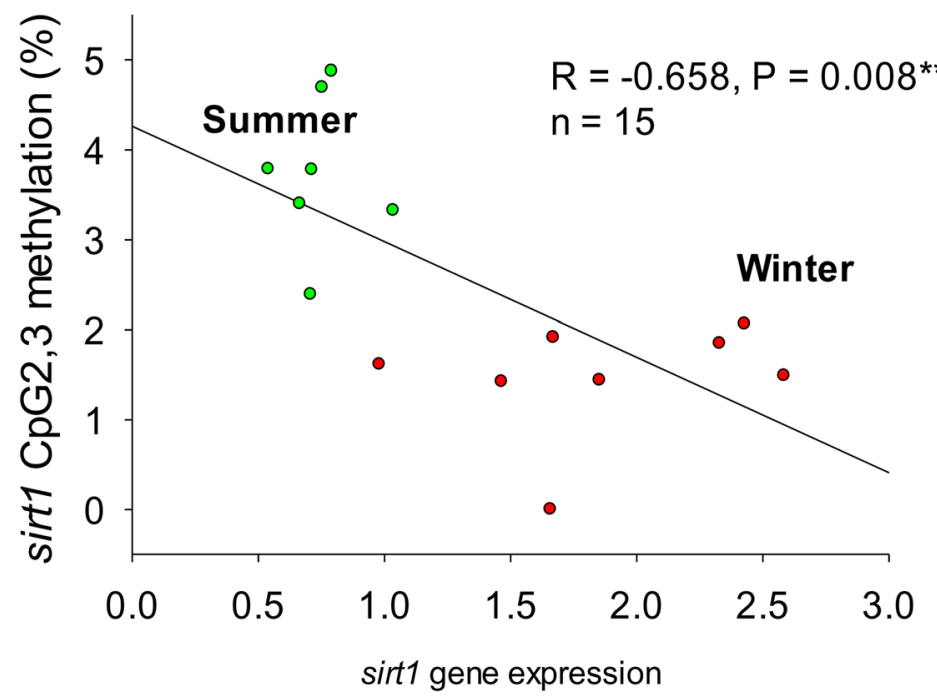

Fig. 7 Seasonal local DNA methylation and correlation with sirt1 gene expression in muscle of one-year-old fish. a Site-specific DNA methylation (\%) of sirt in white skeletal muscle (WSM) of one-year-old fish in winter (black bars) and summer (gray bars). Data are the mean \pm SEM of 8-10 fish. CpG position with a circle indicates significant differences between seasons by t-test $(P<0.05)$. $\mathbf{b}$ Correlation between mean DNA methylation of SP1-related $\mathrm{CpG}$ sites $(\mathrm{CpG} 2,3)$ in the sirt1 gene promoter region and sirt1 gene expression in white skeletal muscle (WSM) of one-year-old fish. Red and green points represent data from winter and summer, respectively

biology and genome stability [8]. However, the epigenetic regulation of SIRTS is less understood, and contradictory results have been reported in different experimental models, with no correlation between SIRT expression and local DNA methylation of CGIs in both humans [54-58] and mice [59]. In contrast, a clear negative correlation between gene expression and CGI hypermethylation has been reported for human SIRT1 [55], and demethylation of bovine SIRT4-6 promoters enhanced their transcriptional activity, favoring the binding of specific TFs to their promoters [60-62]. In the present study, the analyzed CpG sites of sirt3 were hypomethylated irrespective of tissue, age and season, which may indicate that the observed changes in sirt 3 expression (mainly related to season) were not regulated in this fish species by changes in DNA methylation at the analyzed CpG sites. At the hepatic level, the 22 examined CpG sites of CGI sirt1 were also highly refractory to methylation, as occurred in WSM in winter. However, slight changes in DNA methylation were found in the 
Table 1 Relative gene expression of liver and white skeletal muscle (WSM) of gilthead sea bream. Data are the mean \pm SEM of 10 fish of different ages (+3, three-year-old; +1 , one-year-old) sampled in winter $(\mathrm{W})$ and summer $(\mathrm{S})$. P-values are the result of twoway analysis of variance

\begin{tabular}{|c|c|c|c|c|c|c|c|}
\hline & \multicolumn{2}{|l|}{ Winter } & \multicolumn{2}{|l|}{ Summer } & \multicolumn{3}{|c|}{ Two-way ANOVA } \\
\hline & $\overline{W+3}$ & $W+1$ & $S+3$ & $S+1$ & Season & Age & Interaction \\
\hline \multicolumn{8}{|l|}{ LIVER } \\
\hline sirt 1 & $2.53 \pm 0.24$ & $3.22 \pm 0.21$ & $1.02 \pm 0.08$ & $1.52 \pm 0.11$ & $<0.001$ & 0.002 & 0.597 \\
\hline sirt2 & $4.15 \pm 0.33$ & $6.20 \pm 0.46$ & $5.21 \pm 0.27$ & $6.99 \pm 0.27$ & 0.012 & $<0.001$ & 0.697 \\
\hline sirt3 & $1.54 \pm 0.16$ & $1.60 \pm 0.12$ & $0.81 \pm 0.04$ & $0.82 \pm 0.04$ & $<0.001$ & 0.762 & 0.799 \\
\hline sirt4 & $0.59 \pm 0.06$ & $0.64 \pm 0.07$ & $0.34 \pm 0.02$ & $0.48 \pm 0.03$ & $<0.001$ & 0.081 & 0.406 \\
\hline sirt5 & $6.86 \pm 0.54$ & $10.3 \pm 0.52$ & $5.47 \pm 0.21$ & $6.83 \pm 0.26$ & $<0.001$ & $<0.001$ & 0.014 \\
\hline sirt6 & $0.69 \pm 0.08$ & $0.72 \pm 0.05$ & $0.42 \pm 0.03$ & $0.51 \pm 0.05$ & 0.001 & 0.531 & 0.935 \\
\hline sirt7 & $1.07 \pm 0.08$ & $1.17 \pm 0.07$ & $1.11 \pm 0.06$ & $1.20 \pm 0.04$ & 0.177 & 0.385 & 0.795 \\
\hline pgcla & $3.29 \pm 0.90$ & $5.03 \pm 0.63$ & $4.14 \pm 0.33$ & $4.75 \pm 0.32$ & 0.633 & 0.058 & 0.350 \\
\hline cpt1a & $20.1 \pm 3.21$ & $28.7 \pm 2.37$ & $3.94 \pm 0.48$ & $8.57 \pm 0.98$ & $<0.001$ & 0.004 & 0.357 \\
\hline CS & $30.1 \pm 1.95$ & $27.9 \pm 1.18$ & $16.3 \pm 1.84$ & $19.9 \pm 1.32$ & $<0.001$ & 0.666 & 0.077 \\
\hline ucp 1 & $261.4 \pm 16.1$ & $496.2 \pm 44.8$ & $603.2 \pm 45.9$ & $1228.3 \pm 105.9$ & $<0.001$ & $<0.001$ & 0.003 \\
\hline \multicolumn{8}{|l|}{ WSM } \\
\hline sirt 1 & $3.90 \pm 0.30$ & $1.78 \pm 0.17$ & $1.04 \pm 0.09$ & $0.77 \pm 0.05$ & $<0.001$ & $<0.001$ & $<0.001$ \\
\hline sirt2 & $3.23 \pm 0.27$ & $2.10 \pm 0.14$ & $3.44 \pm 0.39$ & $1.96 \pm 0.08$ & 0.884 & $<0.001$ & 0.488 \\
\hline sirt3 & $0.65 \pm 0.06$ & $0.58 \pm 0.06$ & $0.35 \pm 0.06$ & $0.22 \pm 0.01$ & $<0.001$ & 0.081 & 0.548 \\
\hline sirt4 & $0.60 \pm 0.06$ & $0.31 \pm 0.03$ & $0.39 \pm 0.04$ & $0.29 \pm 0.03$ & 0.017 & $<0.001$ & 0.044 \\
\hline sirt5 & $12.9 \pm 1.37$ & $5.19 \pm 0.43$ & $5.48 \pm 1.02$ & $2.72 \pm 0.31$ & $<0.001$ & $<0.001$ & 0.011 \\
\hline sirt6 & $0.55 \pm 0.03$ & $0.31 \pm 0.03$ & $0.32 \pm 0.03$ & $0.18 \pm 0.02$ & $<0.001$ & $<0.001$ & 0.092 \\
\hline sirt7 & $1.77 \pm 0.16$ & $1.00 \pm 0.07$ & $0.71 \pm 0.04$ & $0.43 \pm 0.03$ & $<0.001$ & $<0.001$ & 0.014 \\
\hline pgcla & $6.32 \pm 0.83$ & $4.40 \pm 0.80$ & $2.82 \pm 0.27$ & $2.55 \pm 0.25$ & 0.002 & 0.050 & 0.500 \\
\hline cptia & $71.6 \pm 8.58$ & $49.2 \pm 5.78$ & $4.69 \pm 0.48$ & $9.78 \pm 1.17$ & $<0.001$ & 0.112 & 0.020 \\
\hline CS & $235.2 \pm 19.4$ & $152.0 \pm 12.8$ & $63.9 \pm 3.11$ & $64.9 \pm 4.01$ & $<0.001$ & 0.002 & 0.006 \\
\hline uсp3 & $173.0 \pm 33.1$ & $165.1 \pm 10.8$ & $25.1 \pm 1.74$ & $46.1 \pm 2.38$ & $<0.001$ & 0.794 & 0.498 \\
\hline
\end{tabular}

WSM during summer when fish of the +1 class and the +3 class were compared, and a negative correlation between sirt1 expression and DNA methylation was observed at two CpG positions close to SP1 binding sites $(\mathrm{CpG} 3,19)$. Our results also indicate that the summer decrease in sirt1 expression is concurrent with the increased DNA methylation at the sirt1 promoter, which was especially evident in young fish at $\mathrm{CpG}$ positions containing SP1 binding sites (CpG2, 3 and CpG12-14, 16).

Despite the above correlations, the magnitudes (foldchanges) of age- and season-related changes observed in sirt1 gene expression are difficult to be solely explained by the observed changes in a hypomethylated CGI region, which might be indicative of the contribution of other regulatory mechanisms. Indeed, the presence of several TFBSs (e.g., NF-kB, p53, FOXO1, PPAR CHREBP, HIF1 and C/EBP- $\alpha$ ) at the sirt1 promoter region, in addition to SP1, may contribute to the regulation of sirt1 expression independently of SP1associated methylation. In any case, the association of DNA methylation with an observed phenotype can occur through small differences in the methylation level, often only $1-5 \%$ [65]. Indeed a change in methylation of less than 1\% affects the binding of NRF1 and E2F1 to the SIRT6 promoter in bovine adipocytes [62]. Otherwise, it is well known that age-related changes in DNA methylation patterns are characterized in mammals by global genome hypomethylation and region-specific hypermethylation [66, 67]. Although there is currently no proof that changes in specific DNA methylation patterns of SIRTs can extend lifespan, it is noteworthy that SIRT1 is a master regulator of aging as well as inflammation and metabolism [68, 69]. Hence, alterations in the epigenome in adult somatic tissues might reflect aging-associated deleterious events, but developmental changes in the epigenome might be necessary and fine-tuned by environmental cues. 


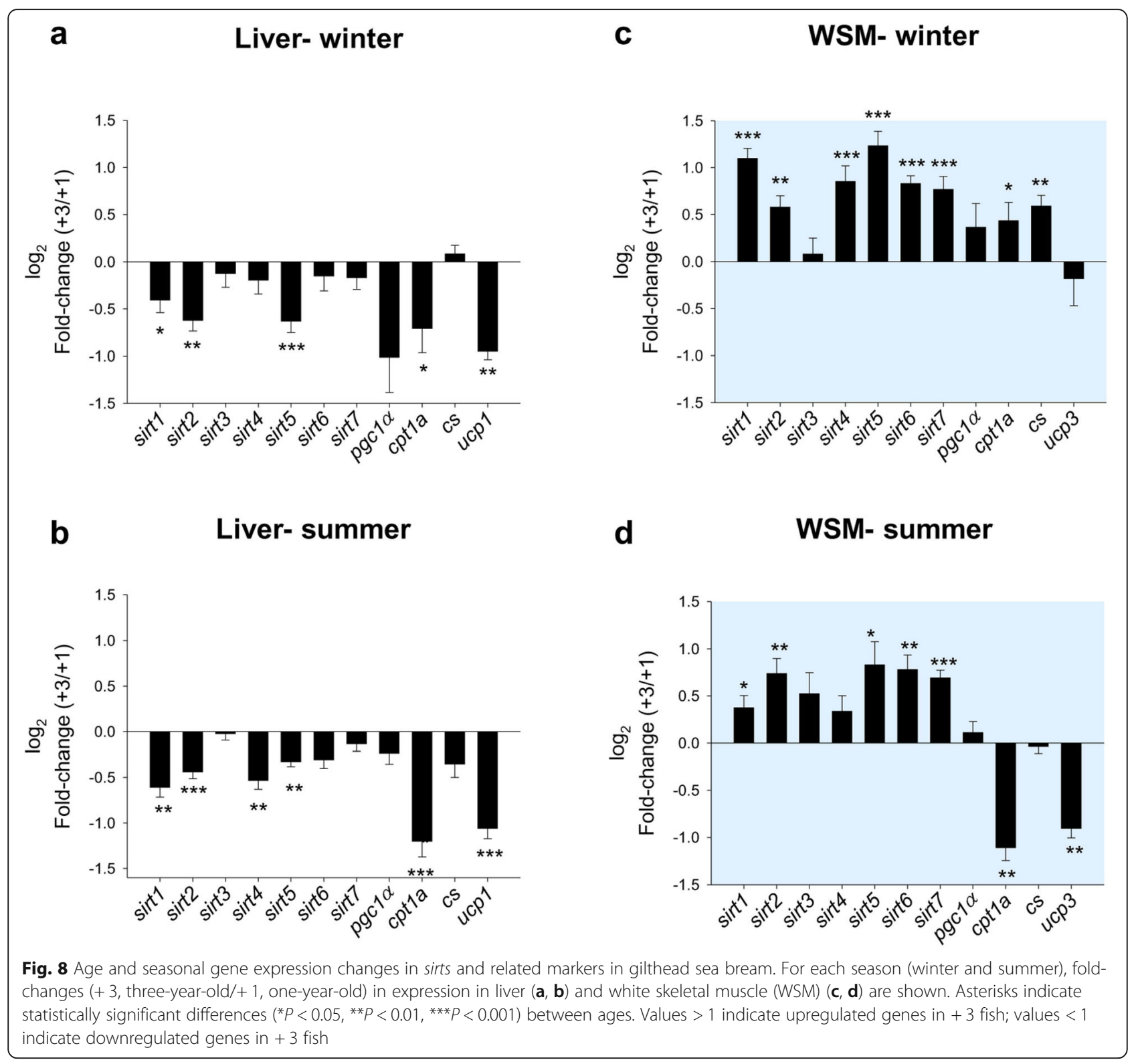

sirt gene expression enables changes in lipogenic and growth energy-demanding processes

The combined gene expression profiling of biomarkers of energy demand ( $p g c 1 \alpha, c p t 1 a, c s$, and ucp 1/3) and energy status (sirt1-7) helps to better discriminate phenotypes with different growth potentials in GSB [4]. Such approaches are also highly informative of the metabolic status of animals across seasons and normal development. In the present study, the hepatic expression of almost all the analyzed markers of energy metabolism was downregulated by age, especially in the cold season. Indeed, differences in feed intake between young and older fish are exacerbated at our latitude from November to March, with voluntary feeding practically stopping in adult fish [70]. Therefore, catabolic states resulting from short-term fasting [11] or natural starvation during winter are sensed by a wide range of energy sensors, including sirts that reflect the energy status rather than the energy demand. In fact, the most energy-demanding process of the liver is lipogenic activity [71], and reduced lipid biosynthetic capabilities during fasting or temperature drops are linked with pronounced downregulated expression of the enzyme subunits of the mitochondrial respiration chain (oxidative phosphorylation pathway, OXPHOS) [30, 72]. This contrasts with the upregulated expression of markers of OXPHOS in the WSM of fasted or feed-restricted GSB $[72,73]$, which reflects an increased tissue-energy demand to preserve the protein muscular mass when young fish face a reduced supply of nutrients or an enhanced energy demand for 
a

\section{Goodness of Fit}

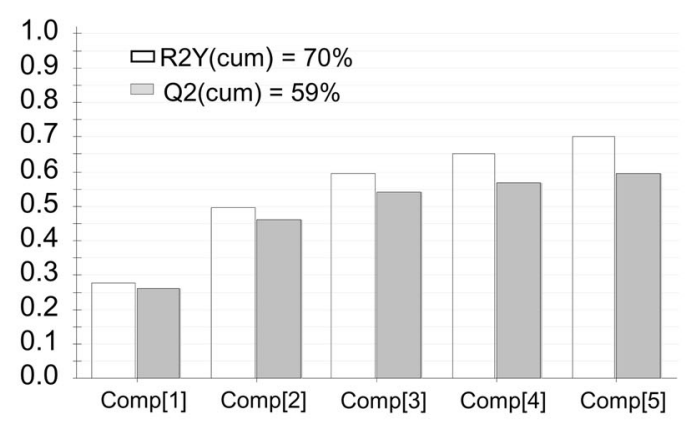

b

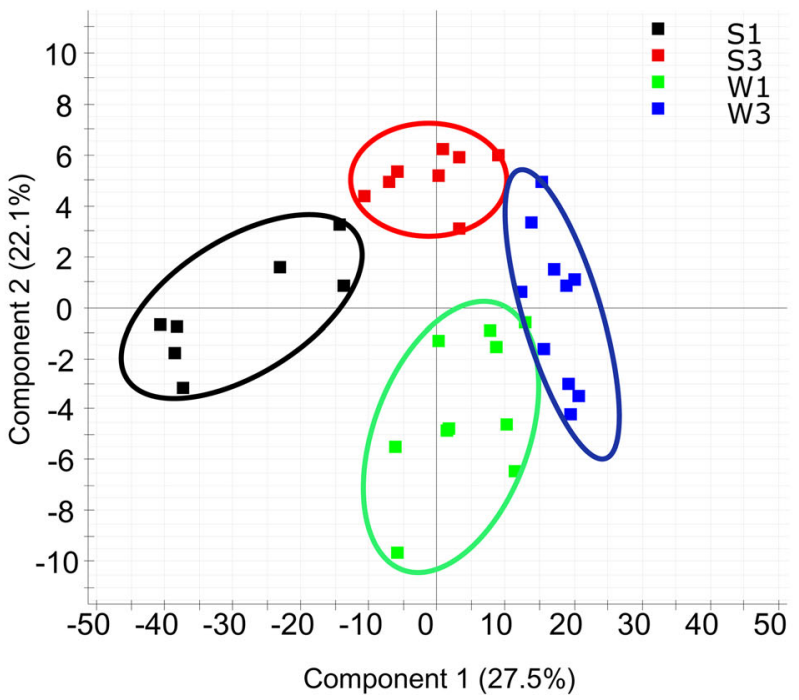

C

\section{Genes, VIP > 1}

\begin{tabular}{lr}
\multicolumn{2}{c}{ After Comp 1 } \\
\hline ucp1 & 3.28 \\
\multicolumn{2}{c}{ After Comp 2 } \\
\hline ucp1 & 2.46 \\
cpt1a & 1.68 \\
cs & 1.02 \\
\hline \multicolumn{2}{c}{ After Comp 3 } \\
\hline ucp1 & 2.25 \\
cpt1a & 1.56 \\
cs & 1.40 \\
\hline After Comp 4 \\
\hline ucp1 & 2.15 \\
cpt1a & 1.50 \\
cs & 1.34 \\
\hline \multicolumn{2}{|c}{ After Comp 5 } \\
\hline ucp1 & 2.07 \\
cpt1a & 1.49 \\
cs & 1.34 \\
sirt5 & 1.05
\end{tabular}

Fig. 9 Discriminant analysis (PLS-DA) of molecular signatures in the liver of gilthead sea bream. Data consist of the relative expression of the 11 genes included in the array from fish of different ages (3, three-year-old; 1, one-year-old) in two seasons (summer, S; winter, W). a Cumulative coefficients of goodness of fit (R2Y, white bars) and prediction (Q2, gray bars) by each component. b PLS-DA score plot of acquired data from fish of +3 and +1 years in summer and winter along the two main components, explaining $49.6 \%$ of the total variance. c Ordered list of markers by variable importance (VIP) in the projection of the PLS-DA model for group differentiation

growth during the summer season [70]. This metabolic feature was illustrated herein by increased expression in young fish of markers of fatty acid $\beta$-oxidation (cpt1a) and muscle respiration uncoupling (ucp 3 ), which evolved to protect mitochondria against oxidative stress in a highly oxidative cellular milieu [74, 75]. Certainly, SIRT1 acts as a major repressor of UCP3 in muscle tissues of rodents [76], also inhibiting the progression of different antioxidant responses mediated by NF- $\mathrm{KB}$ and NRF2 [48]. Conversely, the downregulation of SIRT1 enhances the myogenic gene program to adjust it to energetic demands driven by changing growth, nutrient availability or increased muscle activity [77]. Human studies also indicate that SIRT2 enhances myoblast proliferation [78] and differentiation [79], which is related to the enhanced muscle expression of sirt 2 in juvenile GSB with a higher growth potential [4]. Since these findings are apparently contradictory with the observed upregulated expression of sirt 2 with advancing age, we consider that this agemediated response highlights additional sirt functions related in other animal models to genome maintenance and the avoidance of cell senescence [76, 80, 81]. 
a

\section{Goodness of Fit}

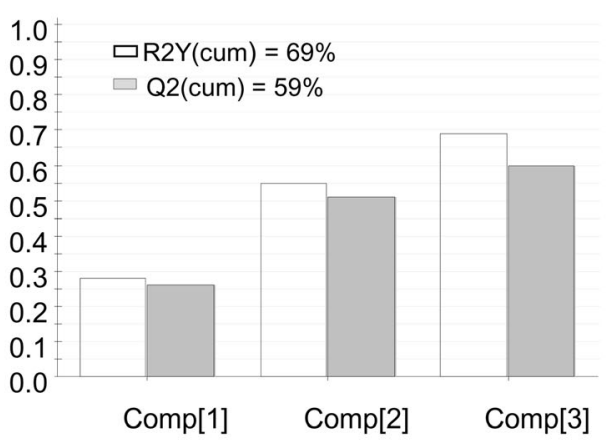

b

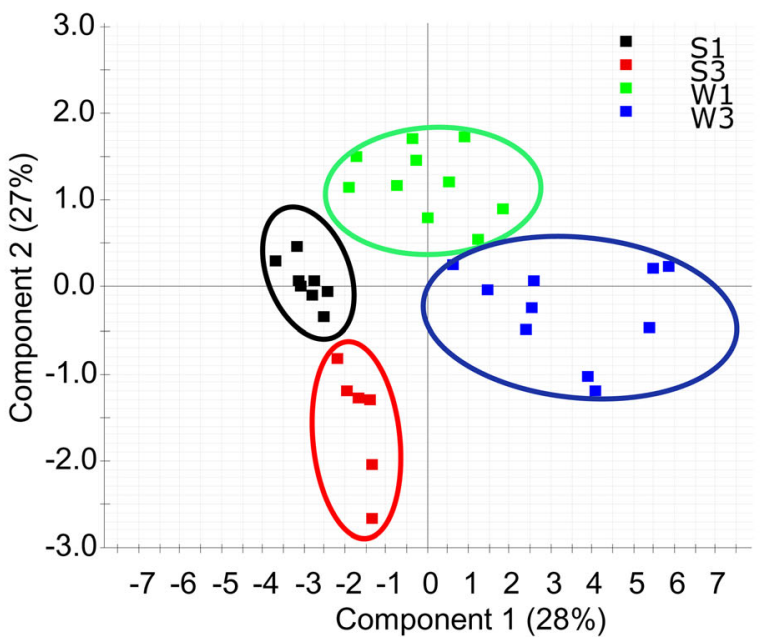

C

\section{Genes, VIP > 1}

\begin{tabular}{lc}
\multicolumn{2}{c}{ After Comp 1 } \\
\hline sirt1 & 1.21 \\
sirt7 & 1.17 \\
cs & 1.15 \\
sirt5 & 1.10 \\
sirt6 & 1.10 \\
cpt1a & 1.06 \\
\hline \multicolumn{1}{c}{ After } & Comp 2 \\
\hline sirt2 & 1.43 \\
ucp3 & 1.22 \\
sirt4 & 1.04 \\
cpt1a & 1.03 \\
\multicolumn{2}{c}{ After Comp 3 } \\
\hline sirt2 & 1.53 \\
sirt3 & 1.21 \\
ucp3 & 1.15
\end{tabular}

Fig. 10 Discriminant analysis (PLS-DA) of molecular signatures in white skeletal muscle of gilthead sea bream. Data consist of the relative expression of the 11 genes included in the array from fish of different ages (3, three-year-old; 1, one-year-old) in two seasons (summer, S; winter, W). a Cumulative coefficients of goodness of fit (R2Y, white bars) and prediction (Q2, gray bars) by each component. $\mathbf{b}$ PLS-DA score plot of acquired data from fish of +3 and +1 years in summer and winter along the two main components, explaining $55 \%$ of the total variance. c Ordered list of markers by variable importance (VIP) in the projection of the PLS-DA model for group differentiation

As a corollary of this complex puzzle, multivariate analyses of gene expression patterns indicate that in our experimental setup, changes in sirt gene expression at the level of WSM are particularly responsive to physiological changes mediated by age and season. Certainly, six sirts out of seven collectively have a discriminant role (in particular sirt1) in disclosing the seasonal-related changes in feed intake and growth performance, as well as the switch in metabolism from glucose utilization to fatty acid oxidation, as reported elsewhere [82]. In other words, our study confirms that sirts are suited to understanding the adjustment of energy metabolism in GSB, although further studies are needed to fully understand their transcriptional regulation.

\section{Conclusions}

This study demonstrates that the gene structure of sirts is highly conserved through vertebrate evolution in the fish lineage. The presence of CGI (sirt1 and sirt3) and non-CGI promoters (sirt2, sirt4-7) was observed in the GSB sirt family, and common regulatory elements in the sirt 1 and sirt3 promoter regions are found in fish and their higher vertebrate counterparts. The gene expression analyses support that GSB sirts, especially sirt1, are 
reliable markers of age- and seasonal-related changes in energy metabolism. Correlation analyses of sirt gene expression and local DNA methylation were performed for the first time in a marine fish, revealing that a slight increase in local DNA methylation contributes to lower sirt1 gene expression in WSM. In particular, methylation at CpG positions containing SP1 binding sites might contribute to season- and age-related changes in sirt1 expression. However, it appears likely that not all changes in sirt1 gene expression can be explained by DNA methylation at the studied CGI region. This is not surprising given that most changes in energy metabolism require a fast response of fish to cope with a poorly predictable environment, which may involve the participation of several regulatory mechanisms.

\section{Supplementary information}

Supplementary information accompanies this paper at https://doi.org/10. 1186/s12983-020-00361-1.

Additional file 1 Table S1. Forward and reverse PCR primers,

pyrosequencing primers and sequences for analysis.

Additional file $\mathbf{2}$ Table S2. Forward and reverse primers for liver and white skeletal muscle pathway-focused qPCR array.

\section{Acknowledgments}

The authors thank M. A. González for technical assistance with gene expression analyses. We acknowledge support of the publication fee by the CSIC Open Access Publication Support Initiative through its Unit of Information Resources for Research (URICI).

\section{Authors' contributions}

JP-S conceived and designed the study. PS-M, EP, and JAC-G performed the experiments. PS-M, EP, JAC-G, and JP-S analyzed the data. PS-M, EP and JP-S wrote the manuscript. The author(s) read and approved the final manuscript.

\section{Funding}

This work was funded by a Spanish MICINN project (BreamAqualNTECH, RTI2018-094128-B-I00) and the PerformFISH (Integrating Innovative Approaches for Competitive and Sustainable Performance across the Mediterranean Aquaculture Value Chain) EU Project (H2020-SFS-2016-2017; 727610). This publication reflects the views only of the authors and the European Commission cannot be held responsible for any use which may be made of the information contained therein. PS-M was supported by a predoctoral research fellowship (BES-2014-069250) from Spanish MINECO. EP was founded by a Postdoctoral Research Fellow (Juan de la CiervaIncorporación, Reference IJCI-2016-27637) from MINECO.

\section{Availability of data and materials}

Not applicable.

\section{Ethics approval and consent to participate}

All procedures of animal rearing and sampling were carried out according to present IATS-CSIC Review Board, European animal directives (2010/63/EU) and Spanish laws (Royal Decree RD53/2013) on the handling of experimental animals.

\section{Consent for publication}

Not applicable.

\section{Competing interests}

The authors declare that they have no competing interests.
Received: 10 March 2020 Accepted: 30 April 2020

Published online: 15 May 2020

\section{References}

1. FAO. The state of world fisheries and aquaculture 2018- Meeting the sustainable development goals. Rome 2018.

2. Chen Y, Gondro C, Quinn K, Herd RM, Parnell PF, Vanselow B. Global gene expression profiling reveals genes expressed differentially in cattle with high and low residual feed intake. Anim Genet. 2011;42:475-90.

3. Choi MJ, Kim GD, Kim JM, Lim HK. Differentially-expressed genes associated with faster growth of the Pacific abalone, Haliotis discus hannai. Int J Mol Sci. 2015;16:27520-34.

4. Simó-Mirabet P, Perera E, Calduch-Giner JA, Afonso JM, Pérez-Sánchez J. Coexpression analysis of sirtuins and related metabolic biomarkers in juveniles of gilthead sea bream (Sparus aurata) with differences in growth performance. Front Physiol. 2018;9:608.

5. Pérez-Sánchez J, Borrel M, Bermejo-Nogales A, Benedito-Palos L, Saera-Vila A, Calduch-Giner JA, et al. Dietary oils mediate cortisol kinetics and the hepatic mRNA expression profile of stress-responsive genes in gilthead sea bream (Sparus aurata) exposed to crowding stress. Implications on energy homeostasis and stress susceptibility. Comp Biochem Physiol Part D Genomics Proteomics. 2013;8:123-30.

6. Benedito-Palos L, Ballester-Lozano GF, Pérez-Sánchez J. Wide-gene expression analysis of lipid-relevant genes in nutritionally challenged gilthead sea bream (Sparus aurata). Gene. 2014;547:34-42.

7. Umehara T, Murase T, Abe Y, Yamashita H, Shibaike Y, Kagawa S, et al. Identification of potential markers of fatal hypothermia by a body temperature-dependent gene expression assay. Int J Legal Med. 2019;133: 335-45.

8. Bosch-Presegué L, Vaquero A. Sirtuin-dependent epigenetic regulation in the maintenance of genome integrity. FEBS J. 2015;282:1745-67.

9. Jing H, Lin H. Sirtuins in epigenetic regulation. Chem Rev. 2015;115:2350-75.

10. Kosciuk T, Wang M, Hong JY, Lin H. Updates on the epigenetic roles of sirtuins. Curr Opin Chem Biol. 2019;51:18-29.

11. Simó-Mirabet P, Bermejo-Nogales A, Calduch-Giner J, Pérez-Sánchez J. Tissue-specific gene expression and fasting regulation of sirtuin family in gilthead sea bream (Sparus aurata). J Comp Physiol B Biochem Syst Environ Physiol. 2017;187:153-63.

12. Simó-Mirabet P, Piazzon MC, Calduch-Giner JA, Ortiz Á, Puyalto M, SitjàBobadilla A, et al. Sodium salt medium-chain fatty acids and Bacillus-based probiotic strategies to improve growth and intestinal health of gilthead sea bream (Sparus aurata). Peer J. 2017;5:e4001.

13. Ryu R, Choi MS. Differences in metabolic biomarkers in the blood and gene expression profiles of peripheral blood mononuclear cells among normal weight, mildly obese and moderately obese subjects. Br J Nutr. 2016;116: 1022-32.

14. García-Giménez JL, Seco-Cervera M, Tollefsbol TO, Romá-Mateo C, PeiróChova L, Lapunzina P, et al. Epigenetic biomarkers: current strategies and future challenges for their use in the clinical laboratory. Crit Rev Clin Lab Sci. 2017:54:529-50.

15. Jablonka E, Lamb MJ. The changing concept of epigenetics. Ann N Y Acad Sci. 2002;981:8296

16. Ibeagha-Awemu EM, Zhao X. Epigenetic marks: regulators of livestock phenotypes and conceivable sources of missing variation in livestock improvement programs. Front Genet. 2015;6:302.

17. Kouzarides T. Chromatin modifications and their function. Cell. 2007;128: 693-705.

18. Moore LD, Le T, Fan G. DNA methylation and its basic function. Neuropsychopharmacology. 2013;38:23-38.

19. D' Alessio AC, Weaver IC, Szyf M. Acetylation-induced transcription is required for active DNA demethylation in methylation-silenced genes. Mol Cell Biol. 2007;27:7462-74.

20. Gavery MR, Roberts SB. Epigenetic considerations in aquaculture. PeerJ. 2017:5:e4147.

21. Navarro-Martín L, Viñas J, Ribas L, Díaz N, Gutiérrez A, Di Croce L, et al. DNA methylation of the gonadal aromatase (cyp19a) promoter is involved in temperature-dependent sex ratio shifts in the European sea bass. PLoS Genet. 2011;7:e1002447.

22. Shao C, Li Q, Chen S, Zhang P, Lian J, Hu Q, et al. Epigenetic modification and inheritance in sexual reversal of fish. Genome Res. 2014;24:604-15. 
23. Morán P, Pérez-Figueroa A. Methylation changes associated with early maturation stages in the Atlantic salmon. BMC Genet. 2011;12:86.

24. Burgerhout $E$, Mommens $M$, Johnsen $H$, Aunsmo A, Santi N, Andersen $\varnothing$. Genetic background and embryonic temperature affect DNA methylation and expression of myogenin and muscle development in Atlantic salmon (Salmo salar). PLoS One. 2017;12:e0179918.

25. Covelo-Soto L, Saura M, Morán P. Does DNA methylation regulate metamorphosis? The case of the sea lamprey (Petromyzon marinus) as an example. Comp Biochem Physiol B Biochem Mol Biol. 2015;185:42-6.

26. Si Y, He F, Wen H, Li J, Zhao J, Ren Y, et al. Genetic polymorphisms and DNA methylation in exon $1 \mathrm{CpG}$-rich regions of PACAP gene and its effect on mRNA expression and growth traits in half smooth tongue sole (Cynoglossus semilaevis). Fish Physiol Biochem. 2016;42:407-21.

27. Li S, He F, Wen H, Li J, Si Y, Liu M, et al. Low salinity affects cellularity, DNA methylation, and mRNA expression of igf1 in the liver of half smooth tongue sole (Cynoglossus semilaevis). Fish Physiol Biochem. 2017:43:1587-602

28. Baerwald MR, Meek MH, Stephens MR, Nagarajan RP, Goodbla AM, Tomalty $\mathrm{KMH}$, et al. Migration-related phenotypic divergence is associated with epigenetic modifications in rainbow trout. Mol Ecol. 2016;25:1785-800

29. Artemov AV, Mugue NS, Rastorguev SM, Zhenilo S, Mazur AM, Tsygankova SV, et al. Genome-wide DNA methylation profiling reveals epigenetic adaptation of stickleback to marine and freshwater conditions. Mol Biol Evol. 2017;34:2203-13.

30. Bermejo-Nogales A, Nederlof M, Benedito-Palos L, Ballester-Lozano GF, Folkedal O, Olsen RE, et al. Metabolic and transcriptional responses of gilthead sea bream (Sparus aurata L.) to environmental stress: new insights in fish mitochondrial phenotyping. Gen Comp Endocrinol. 2014;205:305-15.

31. Melis R, Sanna R, Braca A, Bonaglini E, Cappuccinelli R, Slawski H, et al. Molecular details on gilthead sea bream (Sparus aurata) sensitivity to low water temperatures from $1 \mathrm{H}$ NMR metabolomics. Comp Biochem Physiol A Mol Integr Physiol. 2017;204:129-36.

32. Wattroba M, Dudek I, Skoda M, Stangret A, Rzodkiewicz P, Szukiewicz D. Sirtuins, epigenetics and longevity. Ageing Res Rev. 2017;40:11-9.

33. Illingworth RS, Gruenewald-Schneider U, Webb S, Kerr ARW, James KD, Turner DJ, et al. Orphan CpG islands identify numerous conserved promoters in the mammalian genome. PLoS Genet. 2010;6:e1001134.

34. Solovyev V, Kosarev P, Seledsov I, Vorobyev D. Automatic annotation of eukaryotic genes, pseudogenes and promoters. Genome Biol. 2006;7(Suppl 10):1-12.

35. Knudsen S. Promoter 2.0: for the recognition of Polll promoter sequences. Bioinformatics. 1999;15:356-61.

36. Abeel T, Saeys $Y$, Bonnet E, Rouzé $P$, Van de Peer $Y$. Generic eukaryotic core promoter prediction using structural features of DNA. Genome Res. 2008;18: 310-23

37. Kreft L, Soete A, Hulpiau P, Botzki A, Saeys Y, De Bleser P. ConTra v3: a too to identify transcription factor binding sites across species, update 2017. Nucleic Acids Res. 2017:45:W490-4.

38. Sandoval J, Mendez-Gonzalez J, Nadal E, Chen G, Carmona FJ, Sayols S, et al. A prognostic DNA methylation signature for stage I non-small-cell lung cancer. J Clin Oncol. 2013;31:4140-7.

39. Livak KJ, Schmittgen TD. Analysis of relative gene expression data using real-time quantitative PCR and the 2(-Delta Delta C(T)) method. Methods. 2001;25:402-8

40. Wold S, Sjöström M, Eriksson L. PLS-regression: a basic tool of chemometrics. Chemom Intell Lab Syst. 2001;58:109-30.

41. Li H, Ma M-L, Luo S, Zhang R-M, Han P, Hu W. Metabolic responses to ethanol in Saccharomyces cerevisiae using a gas chromatography tandem mass spectrometry-based metabolomics approach. Int J Biochem Cell Biol. 2012:44:1087-96

42. Kieffer DA, Piccolo BD, Vaziri ND, Liu S, Lau WL, Khazaeli M, et al. Resistant starch alters gut microbiome and metabolomic profiles concurrent with amelioration of chronic kidney disease in rats. Am J Physiol Renal Physiol. 2016;310:F857-71.

43. Greiss S, Gartner A. Sirtuin/Sir2 phylogeny, evolutionary considerations and structural conservation. Mol Cells. 2009;28:407-15.

44. Sauve AA, Wolberger C, Schramm VL, Boeke JD. The biochemistry of sirtuins. Annu Rev Biochem. 2006;75:435-65.

45. Frye RA. Phylogenetic classification of prokaryotic and eukaryotic Sir2-like proteins. Biochem Biophys Res Commun. 2000;273:793-8.
46. Li W, Graur D. Fundamentals of molecular evolution. Sunderland, MA: Sinauer Associates; 1991.

47. Stelzer G, Rosen R, Plaschkes I, Zimmerman S, Twik M, Fishilevich S, et al. The GeneCards suite: from gene data mining to disease genome sequence analysis. Curr Protoc Bioinformatics. 2016;54(Suppl 30):1-33.

48. Buler M, Andersson U, Hakkola J. Who watches the watchmen? Regulation of the expression and activity of sirtuins. FASEB J. 2016;30:3942-60.

49. Deaton AM, Bird A. CpG islands and the regulation of transcription. Genes Dev. 2011;25:1010-22.

50. Han L, Su B, Li WH, Zhao Z. CpG island density and its correlations with genomic features in mammalian genomes. Genome Biol. 2008;9:R79.

51. Han L, Zhao Z. Comparative analysis of CpG islands in four fish genomes. Comp Funct Genomics. 2008;2008:565631.

52. Long HK, King HW, Patient RK, Odom DT, Klose RJ. Protection of CpG islands from DNA methylation is DNA-encoded and evolutionarily conserved. Nucleic Acids Res. 2016;44:6693-706.

53. Sharif J, Endo TA, Toyoda T, Koseki H. Divergence of CpG island promoters: a consequence or cause of evolution? Develop Growth Differ. 2010:52:545-54.

54. Furuya TK, da Silva PN, Payão SL, Rasmussen LT, de Labio RW, Bertolucci PH, et al. SORL1 and SIRT1 mRNA expression and promoter methylation levels in aging and Alzheimer's disease. Neurochem Int. 2012;61:973e5.

55. Hou $Y$, Chen $H, H e ~ Q$, Jiang W, Luo $T$, Duan J, et al. Changes in methylation patterns of multiple genes from peripheral blood leucocytes of Alzheimer's disease patients. Acta Neuropsychiatr. 2013;25:66-76.

56. Sahin K, Yilmaz S, Gozukirmizi N. Changes in human sirtuin 6 gene promoter methylation during aging. Biomed Rep. 2014;2:574e8.

57. Wang L, Zhou H, Wang Y, Cui G, Di LJ. CtBP maintains cancer cell growth and metabolic homeostasis via regulating SIRT4. Cell Death Dis. 2015;6: e1620.

58. Kurylowicz A, Owczarz M, Polosak J, Jonas MI, Lisik W, Jonas M, et al. SIRT1 and SIRT7 expression in adipose tissues of obese and normal-weight individuals is regulated by microRNAs but not by methylation status. Int J Obes (Lond). 2016:40:1635-42.

59. Zullo A, Simone E, Grimaldi M, Gagliardi M, Zullo L, Matarazzo MR, et al. Effect of nutrient deprivation on the expression and the epigenetic signature of sirtuin genes. Nutr Metab Cardiovasc Dis. 2018;28:418-24.

60. Hong J, Wang X, Mei C, Wang H, Zan L. DNA methylation and transcription factors competitively regulate SIRT4 promoter activity in bovine adipocytes: roles of NRF1 and CMYB. DNA Cell Biol. 2019;38:63-75.

61. Hong J, Wang X, Mei C, Zan L. Competitive regulation by transcription factors and DNA methylation in the bovine SIRT5 promoter: roles of E2F4 and KLF6. Gene. 2019;684:39-46.

62. Hong JY, Mei CG, Li SJ, Wang HB, Zhao CP, Zan LS. Coordinate regulation by transcription factors and DNA methylation in the core promoter region of SIRT6 in bovine adipocytes. Arch Biochem Biophys. 2018;659:1-12.

63. Saxonov S, Berg P, Brutlag DL. A genome-wide analysis of CpG dinucleotides in the human genome distinguishes two distinct classes of promoters. Proc Natl Acad Sci U S A. 2006:3(103):1412-7.

64. Smith ZD, Meissner A. DNA methylation: roles in mammalian development. Nat Rev Genet. 2013:14:204.

65. Plagemann A, Harder T, Brunn M, Harder A, Roepke K, Wittrock-Staar M, et al. Hypothalamic proopiomelanocortin promoter methylation becomes altered by early overfeeding: an epigenetic model of obesity and the metabolic syndrome. J Physiol. 2009;587:4963-76.

66. Houtkooper RH, Pirinen E, Auwerx J. Sirtuins as regulators of metabolism and healthspan. Nat Rev Mol Cell Biol. 2012;13:225-38.

67. Jung M, Pfeifer GP. Aging and DNA methylation. BMC Biol. 2015;13:7.

68. Xiao F, Kong QP, Perry B, He YH. Progress on the role of DNA methylation in aging and longevity. Brief Funct Genomics. 2016;15:454-9.

69. Bellet MM, Sassone-Corsi P. Mammalian circadian clock and metabolism the epigenetic link. J Cell Sci. 2010;123:3837-48.

70. Pérez-Sánchez J, Simó-Mirabet P, Naya-Català F, Martos-Sitcha JA, Perera E, Bermejo-Nogales A, et al. Somatotropic axis regulation unravels the differential effects of nutritional and environmental factors in growth performance of marine farmed fishes. Front Endocrinol. 2018:9:687.

71. Rui L. Energy metabolism in the liver. Compr Physiol. 2014;4:177-97.

72. Bermejo-Nogales A, Calduch-Giner JA, Pérez-Sánchez J. Unraveling the molecular signatures of oxidative phosphorylation to cope with the nutritionally changing metabolic capabilities of liver and muscle tissues in farmed fish. PLoS One. 2015;10:e0122889. 
73. Calduch-Giner JA, Echasseriau Y, Crespo D, Baron D, Planas JV, Prunet $P$, et al. Transcriptional assessment by microarray analysis and large-scale meta-analysis of the metabolic capacity of cardiac and skeletal muscle tissues to cope with reduced nutrient availability in gilthead sea bream (Sparus aurata L.). Mar Biotechnol. 2014;16:423-35.

74. Schrauwen-Hinderling VB, Schrauwen P, Hesselink MKC, Van Engelshoven JMA, Nicolay K, Saris WHM, et al. The increase in intramyocellular lipid content is a very early response to training. J Clin Endocr Metab. 2003;88: $1610-6$.

75. Bermejo-Nogales A, Benedito-Palos L, Calduch-Giner JA, Pérez-Sánchez J. Feed restriction up-regulates uncoupling protein 3 (UCP3) gene expression in heart and red muscle tissues of gilthead sea bream (Sparus aurata L.) new insights in substrate oxidation and energy expenditure. Comp Biochem Phys A. 2011;159:296-302.

76. Shoba B, Lwin ZM, Ling LS, Bay BH, Yip GW, Kumar SD. Function of sirtuins in biological tissues. Anat Rec. 2009;292:536-43.

77. Pardo PS, Boriek AM. The physiological roles of Sirt1 in skeletal muscle. Aging. 2011;3:430-7.

78. Wu G, Song C, Lu H, Jia L, Yang G, Shi X, et al. Sirt2 induces C2C12 myoblasts proliferation by activation of the ERK $1 / 2$ pathway. Acta Biochim Biophys Sin. 2014;46:342-5.

79. Stanton DA, Alway SE, Mohamed JS. The role of Sirtuin 2 in the regulation of myogenesis. FASEB J. 2017;31(Suppl 1):877.13.

80. Dryden SC, Nahhas FA, Nowak JE, Goustin AS, Tainsky MA. Role for human SIRT2 NAD-dependent deacetylase activity in control of mitotic exit in the cell cycle. Mol Cell Biol. 2003:23:3173-85.

81. Anwar T, Khosla S, Ramakrishna G. Increased expression of SIRT2 is a novel marker of cellular senescence and is dependent on wild type p53 status. Cell Cycle. 2016;15:1883-97.

82. Lomb DJ, Laurent G, Haigis MC. Sirtuins regulate key aspects of lipid metabolism. Biochim Biophys Acta. 1804;2010:1652-7.

\section{Publisher's Note}

Springer Nature remains neutral with regard to jurisdictional claims in published maps and institutional affiliations.

Ready to submit your research? Choose BMC and benefit from:

- fast, convenient online submission

- thorough peer review by experienced researchers in your field

- rapid publication on acceptance

- support for research data, including large and complex data types

- gold Open Access which fosters wider collaboration and increased citations

- maximum visibility for your research: over $100 \mathrm{M}$ website views per year

At BMC, research is always in progress.

Learn more biomedcentral.com/submissions 